\title{
rMAL Is a Glycosphingolipid-Associated Protein of Myelin and Apical Membranes of Epithelial Cells in Kidney and Stomach
}

\author{
Marcus Frank, Marjan E. van der Haar, Nicole Schaeren-Wiemers, and Martin E. Schwab \\ Research Institute, University of Zurich and Swiss Federal Institute of Technology Zurich, CH-8029 Zurich, Switzerland
}

rMAL, the rat myelin and lymphocyte protein, is a small hydrophobic protein of $17 \mathrm{kDa}$ with four putative transmembrane domains and is expressed in oligodendrocytes and Schwann cells, the myelinating cells of the nervous system. In addition, transcript expression has been found in kidney, spleen, and intestine. Confocal microscopy and immunoelectron microscopy with an affinity-purified antibody localized rMAL to compact myelin in a pattern similar to the structural myelin proteins: myelin basic protein and proteolipid protein. In kidney and stomach epithelia, rMAL is located almost exclusively on the apical (luminal) membranes of the cells lining distal tubuli in kidney and the glandular part of the stomach. Biochemical analysis of plasma membranes isolated from spinal cord and kidney demonstrated that $\mathrm{rMAL}$ is a proteolipid that is present

Four transmembrane domain (4TM) proteins fulfill various important biological functions in different cell types and tissues. Myelin proteins with this structure are the proteolipid protein (PLP) in the CNS (Nave and Milner, 1989) and the peripheral myelin protein (PMP 22) in the PNS (Snipes et al., 1992; Snipes and Suter, 1995a). Similarly, connexin 32, which belongs to the connexin family (for review, see Bennett et al., 1991; Dermietzel and Spray, 1993), is expressed in central and peripheral myelin (Scherer et al., 1995). Mutations in either of these genes cause severe neuropathies in humans and transgenic animal models (for review, see Nave, 1994; Snipes and Suter, 1995b; Scherer, 1997). Additionally, many lymphocyte membrane proteins are known to have a 4TM structure (Wright and Tomlinson, 1994). One of these proteins, CD9, was found to be expressed in oligodendrocytes and Schwann cells (Tole and Patterson, 1993; Kaprielian et al., 1995; Kawaga et al., 1997).

Differential screening for new oligodendrocyte genes in our laboratory resulted in the identification of a new myelin protein with four putative transmembrane domains (Schaeren-Wiemers et al., 1995a,b). Sequence analysis showed that it was the rat homolog of the MAL protein, previously cloned from human T-cell lines (Alonso and Weissman, 1987). Northern and in situ

\footnotetext{
Received Jan. 26, 1998; revised March 23, 1998; accepted April 9, 1998.

M.E.v.d.H. was supported by the Dutch Foundation for Multiple Sclerosis. This study was supported by the Swiss National Science Foundation (Grant 31-45549.95). We thank our colleague Dr. Anne McKinney for assistance and precious help with the confocal microscopy and imaging. We acknowledge the photographic work of Roland Schoeb and the help of Eva Hochreuter in editing the figures. We thank our colleagues Dr. Christine Bandtlow and Dr. Adrian Spillmann for many suggestions and helpful discussions.

Correspondence should be addressed to Marcus Frank, Brain Research Institute, University of Zurich and Swiss Federal Institute of Technology Zurich, AugustForel-Strasse 1, CH-8029 Zurich, Switzerland.

Dr. Schaeren-Wiemers's present address: University Hospital, Department of Research, Neurobiology, Hebelstrasse 20, CH-4031 Basel, Switzerland. Copyright (C) 1998 Society for Neuroscience $\quad 0270-6474 / 98 / 184901-13 \$ 05.00 / 0$
}

in detergent insoluble complexes typical for proteins associated with glycosphingolipids. Lipid and protein analysis showed a co-enrichment of glycosphingolipids and rMAL protein within these complexes, indicating a close association of rMAL to glycosphingolipids in myelin and in kidney in vivo.

We conclude that specific rMAL-glycosphingolipid interactions may lead to the formation and maintenance of stable protein-lipid microdomains in myelin and apical epithelial membranes. They may contribute to specific properties of these highly specialized plasma membranes.

Key words: myelin; proteolipid; glycosphingolipid; kidney epithelium; stomach epithelium; lymphocyte; galactosylceramide; sulfatide hybridization analysis showed specific expression of the rMAL transcript in oligodendrocytes and Schwann cells with a peak during myelin formation. Thus, the name MAL was reinterpreted as myelin and lymphocyte protein (Schaeren-Wiemers et al., 1995b). Immunocytochemistry and Western blot analysis showed the presence of rMAL protein in myelinated tissues. In the CNS the onset of rMAL protein expression is similar to that of PLP, i.e., lagging behind the expression of myelin basic protein (MBP). In contrast in the PNS, rMAL expression precedes MBP expression and is detected before birth (M. Frank, unpublished observations). Independently, rMAL was identified as a developmentally regulated protein in differentiated cultured rat oligodendrocytes (Kim et al., 1995).

Outside the nervous system rMAL transcripts were detected in spleen and kidney (Kim et al., 1995; Schaeren-Wiemers et al., 1995b). Recently, Northern blot analysis of mouse tissues showed expression of MAL transcripts in various parts of the intestine, e.g., in stomach (Magyar et al., 1997). Canine MAL (VIP 17) was isolated as a detergent-insoluble protein from transport vesicles of Madin-Darby canine kidney (MDCK) cells (Zacchetti et al., 1995).

The function of MAL protein in myelin and the other tissues remained unclear so far. A striking common feature of all the tissues that express MAL protein is their high content of particular glycosphingolipids. Although CNS and PNS myelin differ widely in their protein composition, glycosphingolipids, e.g., galactosylceramide and sulfatide, are the major lipid components of both types of myelin (Morell, 1984). Moreover, glycosphingolipids are an important constituent of specialized apical membranes of kidney and stomach (Shayman and Radin, 1991; Lande et al., 1994), and finally, glycolipid-enriched membranes are also found in T-cells (Kiguchi et al., 1990).

Our biochemical analysis shows that rMAL protein is tightly 
associated with glycosphingolipids, when isolated from tissues expressing rMAL protein in vivo. Specific rMAL-glycosphingolipid interactions may lead to the formation and maintenance of specialized membrane microdomains in myelin and apical membranes of kidney and stomach and may contribute to the special properties of these membranes.

\section{MATERIALS AND METHODS}

Animals and tissues. Postnatal and adult Lewis rats were decapitated, and the tissues were rapidly dissected and snap-frozen in liquid nitrogen for RNA extraction or embedded in tissue tek (Sakura, Torrance, CA) and frozen at $-40^{\circ} \mathrm{C}$ in isopentane for in situ hybridization. For immunocytochemistry, the rats were deeply anesthetized with pentobarbital (200 $\mathrm{mg} / \mathrm{kg}$ Nembutal; Abbott, North Chicago, IL) and perfused intracardially with a fixative containing $4 \%$ paraformaldehyde in $0.1 \mathrm{~m}$ phosphate buffer with $5 \%$ sucrose. The tissue was post-fixed in the same fixative overnight, immersed in $30 \%$ sucrose, embedded in tissue tek, and frozen at $-40^{\circ} \mathrm{C}$ in isopentane.

Chemicals, probes, and $c D N A$. The chemicals used were obtained from Sigma and Fluka (Buchs, Switzerland) unless indicated otherwise. Digoxigenin-labeled riboprobes were generated from pBluescript SKvector (Stratagene, La Jolla, CA, ) containing the full-length sequence of rMAL cDNA (Schaeren-Wiemers et al., 1995b) with T3 (antisense) and T7 (sense) RNA polymerase, using digoxigenin-UTP (Boehringer Mannheim, Mannheim, Germany) according to the manufacturer's instructions. For in situ hybridization the labeled probes were alkali-hydrolyzed to a length of $\sim 200$ bases (Schaeren-Wiemers and Gerfin-Moser, 1993). For transient transfection of COS 7 cells, a HindIII/XbaI fragment containing the full-length rMAL sequence was cut out from Bluescript vector and subcloned into the expression vector $\mathrm{pCMX}$ provided by Dr. G. D. Yancopoulos (Regeneron Pharmaceutical Inc., Tarrytown, NY) (Davis et al., 1991).

Northern blot analysis. Total RNA from tissues of postnatal rats was isolated from tissue powder made on dry ice in a mortar using a RNeasy kit (Qiagen, Hilden, Germany). Total RNA $(2 \mu \mathrm{g})$ was separated on $1.2 \%$ agarose/formaldehyde gels and pressure-blotted to nylon membranes (Genescreen/Dupont, Boston, MA). Hybridization was performed overnight at $68^{\circ} \mathrm{C}$ in $5 \times$ sodium salt citrate buffer [(SSC) $1 \times$ SSC: $0.15 \mathrm{M}$ $\mathrm{NaCl}, 0.05 \mathrm{M}$ sodium citrate, $\mathrm{pH} 7.0$ ] containing $50 \%$ formamide, $0.02 \%$ SDS, $0.1 \% N$-lauroylsarcosine, and $2 \%$ blocking reagent (Boehringer Mannheim) (10\% stock solution in maleic acid buffer). Two stringent washes were done in $0.1 \times \mathrm{SSC} / 0.1 \% \mathrm{SDS}$ at $68^{\circ} \mathrm{C}$ for $1 \mathrm{hr}$. Detection was performed with alkaline phosphatase-coupled anti-digoxigenin antibodies (Boehringer Mannheim) and revealed with a chemiluminescent substrate (CSPD; Tropix, Bedford, MA).

In situ hybridization. Cryostat sections $(15 \mu \mathrm{m})$ of fresh frozen rat tissue were collected on superfrost-plus slides (Menzel-Gläser, Braunschweig, Germany) and processed as described earlier (SchaerenWiemers and Gerfin-Moser, 1993) with minor modifications. Briefly, sections were post-fixed in $4 \%$ paraformaldehyde/PBS, acetylated in 0.1 $\mathrm{M}$ triethanolamine $/ 0.25 \%$ acetic anhydride, and permeabilized for $10 \mathrm{~min}$ (nervous system tissues) or 5 min (kidney, spleen) in $1 \%$ Triton X-100/ PBS. After prehybridization for $3 \mathrm{hr}$ at room temperature, the sections were hybridized overnight at $68^{\circ} \mathrm{C}$ with sense or antisense digoxigeninlabeled probes in hybridization buffer containing $5 \times$ SSC, $50 \%$ formamide, and 2\% blocking reagent (Boehringer Mannheim). Stringent washes were done in $0.2 \% \mathrm{SSC}$ at $68^{\circ} \mathrm{C}$, and hybridization signals were visualized after incubation with alkaline phosphatase-coupled antidigoxigenin antibodies (Boehringer Mannheim) using nitroblue tetrazolium (NBT) and 5-bromo-4-chloro-3-indolylphosphate (BCIP) as a color reaction substrate.

COS cell transfection. COS cell transfection was performed as described previously (Schaeren-Wiemers et al., 1995c). The transfected COS cells were fixed after 48 and $60 \mathrm{hr}$ with $4 \%$ paraformaldehyde in PBS, permeabilized with $0.1 \%$ saponin, $0.1 \%$ Tween 20 , or $0.1 \%$ Triton $\mathrm{X}-100$ in PBS, blocked with 5\% normal goat serum in PBS for $1 \mathrm{hr}$, and processed for immunocytochemistry as described for the kidney using FITC-coupled secondary antibodies (Jackson ImmunoResearch, West Grove, PA).

Antibodies. Synthesis of peptides and immunization of rabbits was done by Research Genetics (Huntsville, AL) using the 13 mer peptide MFDGFTYRHYHEN corresponding to amino acids $114-126$ of rMAL protein as described previously (Schaeren-Wiemers et al., 1995b). Immunizations were also done in our laboratory using this peptide with the RIBI adjuvans system (RIBI Immunochemicals, Hamilton, MT), with a similar result. The rabbit antisera were affinity-purified over a peptide-Sepharose 4B column with the peptide linked by residues DKDK at the $\mathrm{C}$ terminus (Research Genetics) according to standard protocols (Harlow and Lane, 1988). Specific antibodies were obtained from the salt-washed (500 mM NaCl) column in the acidic, $\mathrm{pH} 2.5$, and basic, $\mathrm{pH}$ 11.5, elution steps. Antibodies obtained in the basic elution step were used in this study.

Immunochemistry. Cryosections $(20 \mu \mathrm{m})$ were collected on superfrostplus slides. Staining of nervous system tissue was performed as described (Schaeren-Wiemers et al., 1995b), with only minor modifications. Briefly, sections were permeabilized with ice-cold $95 \%$ ethanol, $5 \%$ acetic acid for $25 \mathrm{~min}$ and rehydrated in PBS blocked for $1 \mathrm{hr}$ with PBS containing $0.1 \%$ cold-water fish gelatin (Aurion, Wageningen, The Netherlands), $2.5 \%$ normal goat serum, and $0.05 \%$ saponin. This blocking buffer was also used for all antibody dilution steps, whereas PBS was used for the washing steps. For peptide competition, the antibody was preincubated for $2 \mathrm{hr}$ with the immunogen peptide $(0.25 \mu \mathrm{g} / \mu \mathrm{l})$. For kidney and other non-neural tissues, ethanol permeabilization has been omitted, and sections were blocked for $1 \mathrm{hr}$ with PBS containing 5\% normal goat serum and $0.1 \%$ saponin. Antibodies were diluted in the same buffer without saponin. Affinity-purified anti-rMAL antiserum was used at a concentration of $5 \mu \mathrm{g} / \mathrm{ml}$. Monoclonal antibodies against MBP (Boehringer Mannheim) and PLP (Boehringer Ingelheim) were used at a dilution of 1:500. The primary antibodies were incubated overnight at $4^{\circ} \mathrm{C}$ or for $2 \mathrm{hr}$ at room temperature. Secondary anti-rabbit biotinylated antibodies (Vector, Burlingame, CA) and fluorescent-labeled antibodies (Jackson) were diluted 1:200 and incubated for $1.5 \mathrm{hr}$. With use of the ABC kit (Vector), immunosignals were developed with $\mathrm{DAB}$ as a chromogen. For doublestaining experiments, primary and secondary antibodies were applied simultaneously. Primary antibodies were omitted in the controls. The sections were analyzed with a Zeiss LSM 410 inverted scanning confocal microscope, using a Zeiss Apofluor $40 \times 1.3$ numerical aperture oil immersion lens. For visualization of the fluorescence signals, an $\mathrm{HeNe}$ laser pretuned to $543 \mathrm{~nm}$ and an argon laser pretuned to $488 \mathrm{~nm}$ were used. A bandpass filter of $590-610 \mathrm{~nm}$ and a dichroic beam splitter of $488 / 543$ were selected to obtain the images from double-labeling experiments. Optical sections $(0.15-0.2 \mu \mathrm{m})$ were transferred to a Silicon Graphics Indigo2 Extreme (Silicon Graphics Inc., Mountain View, CA) for processing (Imaris, Bitplane AG, Zurich, Switzerland).

Semithin sections and electron microscopy. Cryostat sections (30 or 50 $\mu \mathrm{m})$ were collected in PBS and for immunocytochemistry and processed as described above, with prolonged washing steps on a rocker. Signal detection was done using the ABC method (Vector) or secondary antibodies (diluted 1:100) coupled to colloidal gold of $10 \mathrm{~nm}$ (kidney) or 0.8 $\mathrm{nm}$ (brain, spinal roots) size with silver enhancement (Aurion). Sections were post-fixed in $1 \%$ osmiumtetroxide, dehydrated in ethanol and propylenoxide, and embedded in Araldite (Serva, Heidelberg, Germany). Semithin sections $(0.5 \mu \mathrm{m})$ and ultrathin sections $(50-90 \mathrm{~nm})$ were cut. Ultrathin sections were contrasted with uranyl acetate and viewed in a Zeiss 902 electron microscope operated at $50 \mathrm{kV}$.

Preparation of membrane fractions and detergent extraction. Kidney, spinal cord, and brainstem of eight postnatal day (P) 14 rats were homogenized in $2-3 \mathrm{ml}$ of buffer containing $250 \mathrm{~mm}$ sucrose, $10 \mathrm{mM}$ HEPES/NaOH, pH 7.4, and 2 mM EGTA supplemented with protease inhibitors (aprotinin, leupeptin, pepstatin, and PMSF). Sucrose was added to the homogenized samples to a final concentration of $2 \mathrm{M}$ at a final volume of $6 \mathrm{ml}$ and dissolved at $4^{\circ} \mathrm{C}$. The homogenates were overlaid with $18 \mathrm{ml}$ of $1.2 \mathrm{M}$ sucrose and $6 \mathrm{ml}$ of $0.8 \mathrm{M}$ sucrose in $10 \mathrm{~mm}$ HEPES, pH 7.4, and $2 \mathrm{mM}$ EGTA, and centrifuged for $20 \mathrm{hr}$ at 25000 $\operatorname{rpm}(\sim 120,000 \times g)$ at $4^{\circ} \mathrm{C}$ in a SW28 rotor (Beckman Instruments, Palo Alto, CA). The optically dense membrane material present at the $0.8 / 1.2$ $\mathrm{M}$ sucrose interface was collected in a total volume of $4 \mathrm{ml}$ and either was diluted with $30 \mathrm{ml}$ HEPES buffer and pelleted by centrifugation for 1.5 $\mathrm{hr}$ at $25,000 \mathrm{rpm}$ at $4^{\circ} \mathrm{C}$ in the SW28 rotor or extracted with $3-[(3-$ cholamidopropyl)dimethyl-ammonio]-1-propane sulfonate (CHAPS) following the protocol by Fiedler et al. (1993) with minor modifications. Briefly, $4 \mathrm{ml}$ of total cellular membranes was extracted with $20 \mathrm{~mm}$ CHAPS, $50 \mathrm{~mm}$ Tris-HCl, pH 7.4, in a total volume of $10 \mathrm{ml}$ for $30 \mathrm{~min}$ on ice. The extract was overlaid onto $10 \mathrm{ml}$ of $0.9 \mathrm{M}$ sucrose in $10 \mathrm{~mm}$ CHAPS, $50 \mathrm{~mm}$ Tris-HCl, pH 7.4, and centrifuged for $2 \mathrm{hr}$ at 25,000 rpm (SW28) and $4^{\circ} \mathrm{C}$. The pellet was solubilized in $25 \mathrm{~mm}$ Tris-HCl, $\mathrm{pH} 8.3$, $0.192 \mathrm{M}$ glycine, and $0.1 \%$ SDS (solubilization buffer) (Skibbens et al., 1989).

Chloroform/methanol extraction. To $100 \mu \mathrm{l}$ of solubilized membranes, 
from either the total membrane fraction or the CHAPS-extracted membranes, $1 \mathrm{ml}$ of chloroform and $500 \mu \mathrm{l}$ of methanol were added and incubated at $4^{\circ} \mathrm{C}$ with rotation for $50 \mathrm{~min}$. Then $300 \mu \mathrm{l}$ of water was added, and the samples were incubated for another $30 \mathrm{~min}$ at $4^{\circ} \mathrm{C}$. The samples were centrifuged at 13,000 rpm in an Eppendorf centrifuge, the water phase was removed, the organic phase was transferred to a clean tube and washed with a water/methanol (3:5) mixture. Supernatants of the CHAPS extraction were extracted with 3 vol of chloroform/methanol $2: 1$, incubated at $4^{\circ} \mathrm{C}$ with rotation for $50 \mathrm{~min}$ and centrifuged for $5 \mathrm{~min}$ at $7000 \mathrm{rpm}$ in a tabletop centrifuge, and the water phase was removed. The organic phases were dried in a speedvac and taken up in either solubilization buffer for SDS-PAGE or in chloroform/methanol (2:1) for lipid analysis.

Lipid analysis. The lipids were separated by thin layer chromatography (TLC) on aluminum-backed silica sheets (Silica 60; Merck, Darmstadt, Germany) in chloroform $/$ methanol $/ \mathrm{H}_{2} \mathrm{O}(60: 25: 4, \mathrm{v} / \mathrm{v} / \mathrm{v})$. The sheets were dried by air, sprayed with orcinol (Sigma), dried, and developed for $10 \mathrm{~min}$ at $100^{\circ} \mathrm{C}$. Commercial lipid and glycosphingolipid standards (Sigma) were run in parallel on the same TLC.

SDS-PAGE and Western blotting. The protein concentration of the samples was determined by the Bio-Rad Protein dye using a Bio-Rad microplate scanner (Bio-Rad, Hercules, CA). Samples to be analyzed by PAGE were dissolved in sample buffer $(50 \mathrm{~mm}$ Tris, $\mathrm{pH} 6.8,10 \%$ glycerol, $1 \% \mathrm{SDS}$, and $10 \mu \mathrm{M}$ EDTA) and run on $15 \%$ polyacrylamide gels using the Bio-Rad Mini-Protean II electrophoresis cell. Proteins were detected by silver-stain or transferred to Immobilon-P membranes (Millipore, Bedford, MA) by semi-dry blotting (Bio-Rad). After they were blocked in TBS containing $0.2 \%$ Triton X-100 (TBST) and 1\% gelatin hydrolysate (DGF, Eberbach, Germany), the membranes were incubated with anti-rMAL antibodies $(2.5 \mu \mathrm{g} / \mathrm{ml})$, anti-PLP antibody (Immunodiagnostics Inc., Bedford, MA) (diluted 1:500), or O1 or O4 hybridoma supernatant (Sommer and Schachner, 1981) (gift from Dr. M. Schachner, University of Hamburg) diluted 1:10 and 1:5, respectively, overnight at $4^{\circ} \mathrm{C}$. After they were washed in TBST, signal detection was performed by incubation with horseradish peroxidase-labeled (Amersham, Buckinghamshire, UK) or alkaline phosphatase-labeled secondary antibodies (Jackson) using chemiluminescent reagents (Amersham) or $\mathrm{BCIP} / \mathrm{NBT}$ as a substrate.

\section{RESULTS}

\section{Specificity of rMAL peptide antibody}

Rabbit antisera were raised against a 13 amino acid peptide corresponding to the loop between the third and fourth hydrophobic domain of rMAL (Schaeren-Wiemers et al., 1995b). This sequence was predicted to be extracellular according to the model proposed for MAL protein (Alonso and Weissman, 1987; Schaeren-Wiemers et al., 1995b). The antiserum was affinitypurified on a peptide column, and its specificity was verified by detection of recombinant $\mathrm{rMAL}$ protein in COS cells transfected with rMAL cDNA (Fig. 1). Immunopositive cells were observed only in dishes that were transfected with rMAL cDNA (Fig. $1 A, C)$ but not in cells mock-transfected with the vector alone (Fig. $1 B, D)$. With very mild permeabilization ( $0.02 \%$ saponin), sole staining of the plasma membrane was observed. After harsher permeabilization with $0.1 \%$ Tween 20 , prominent granular perinuclear staining, presumably in the endoplasmic reticulum, in the Golgi system, and in vesicular structures, was observed. These results confirm the specificity of our antibodies and suggest that the peptide sequence used as an antigen is most likely located on an extracellular loop of rMAL (see Fig. 7D).

\section{Localization of rMAL protein in the CNS and PNS}

The affinity-purified antiserum was used to investigate the expression pattern of rMAL protein in brain, spinal cord, and peripheral nerves. Intense immunoreactivity was observed in all myelinated regions of the CNS and PNS of the adult rat. Interestingly, MAL immunoreactivity was consistently stronger in the PNS than in the CNS. An example of rMAL immunostaining in the CNS is shown for the adult rat cerebellum (Fig. 2A). Pretreat-
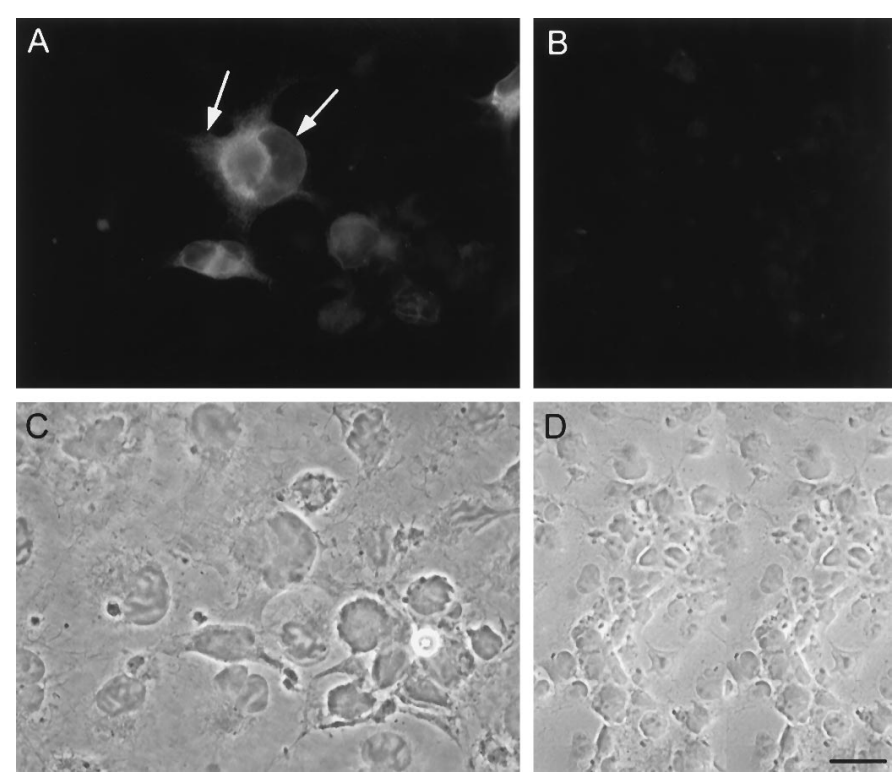

Figure 1. Specific staining of anti-rMAL antibody on transfected COS cells. COS-7 cells were transiently transfected with a eukaryotic expression vector containing full-length $\operatorname{rMAL} \mathrm{cDNA}(A, C)$ or with the vector alone $(B, D)$. After $48 \mathrm{hr}$ in culture the cells were permeabilized with $0.1 \%$ Tween 20 and stained with the affinity-purified anti-rMAL antibody followed by an FITC-labeled secondary antibody $(A)$. rMAL protein is detected mainly in the perinuclear area and on the plasma membrane (lammelipodia, filopodia; arrows) of the transfected cells. Labeling is absent in the mock-transfected cells $(B) . C$ and $D$ show the corresponding fields in phase contrast. Only $\sim 20 \%$ of the COS cells express rMAL $(A$, $C$ ). Scale bar (shown in $D$ ): $A, C, 30 \mu \mathrm{m} ; B, D, 60 \mu \mathrm{m}$.

ment of the antibodies with the corresponding peptide abolished the immmunostaining (Fig. $2 B$ ). Immunostaining of consecutive sections (Fig. 2C) for MBP revealed a pattern similar to that of rMAL protein. Cross sections of the spinal cord were doublestained with antibodies against rMAL and PLP using two different fluorochromes for the secondary antibodies (Fig. 3). Confocal microscopy and analysis of single optical sections showed a nearly identical staining of white matter and some axons/axon fascicles, although rMAL immunoreactivity was consistently weaker than PLP immunoreactivity (Fig. $3 A, B$ ). A high degree of colocalization of PLP and rMAL could be demonstrated along the myelin sheath of single axons, e.g., in the substantia gelatinosa (Fig. 3C, arrow). Comparable results were obtained with $\mathrm{rMAL}$ and MBP immunostainings in the spinal cord (data not shown). In the PNS, double-staining experiments for MBP and $\mathrm{MMAL}$ revealed the same pattern of ring-like structures of myelin sheaths around the axons (Fig. 3D,E). Double exposure showed widespread colocalization of both proteins in compact myelin (Fig. $3 F$ ).

At the ultrastructural level, using preembedding immunocytochemistry with gold-coupled secondary antibodies and silver intensification, frequent labeling for rMAL of myelin sheaths of sciatic nerve axons was seen (Fig. 4). The gold particles were located all over the myelin sheaths; no restriction to the axonal or abaxonal membranes or any other specialized part of the myelin was observed (Fig. 4, arrows). Similar results were obtained for myelin of optic nerve and cerebellum (data not shown). Most of the immunoreactivity was seen whenever the compact myelin was disrupted by the typical permeabilization and fixation artifacts (Fig. 4). Indeed, disruption of the compact myelin seemed a prerequisite for an efficient labeling of rMAL protein in compact myelin. In line with these observations, no labeling could be 


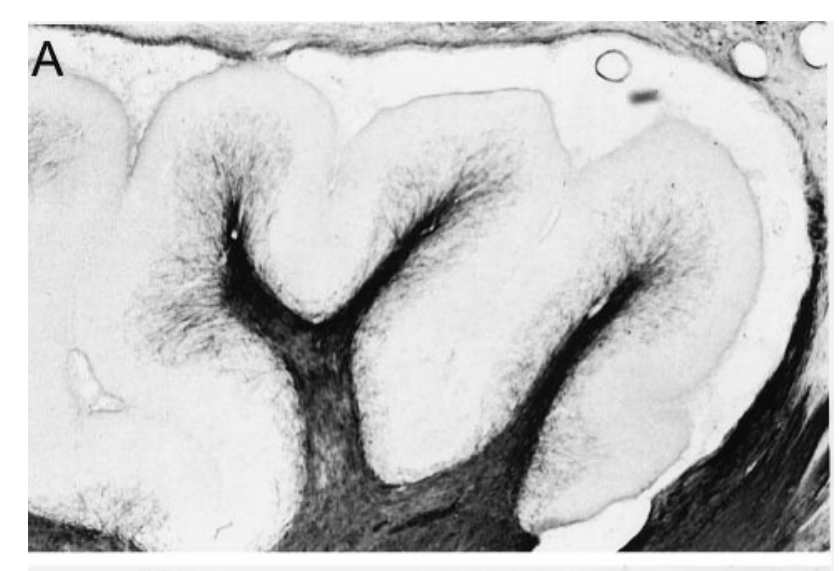

B

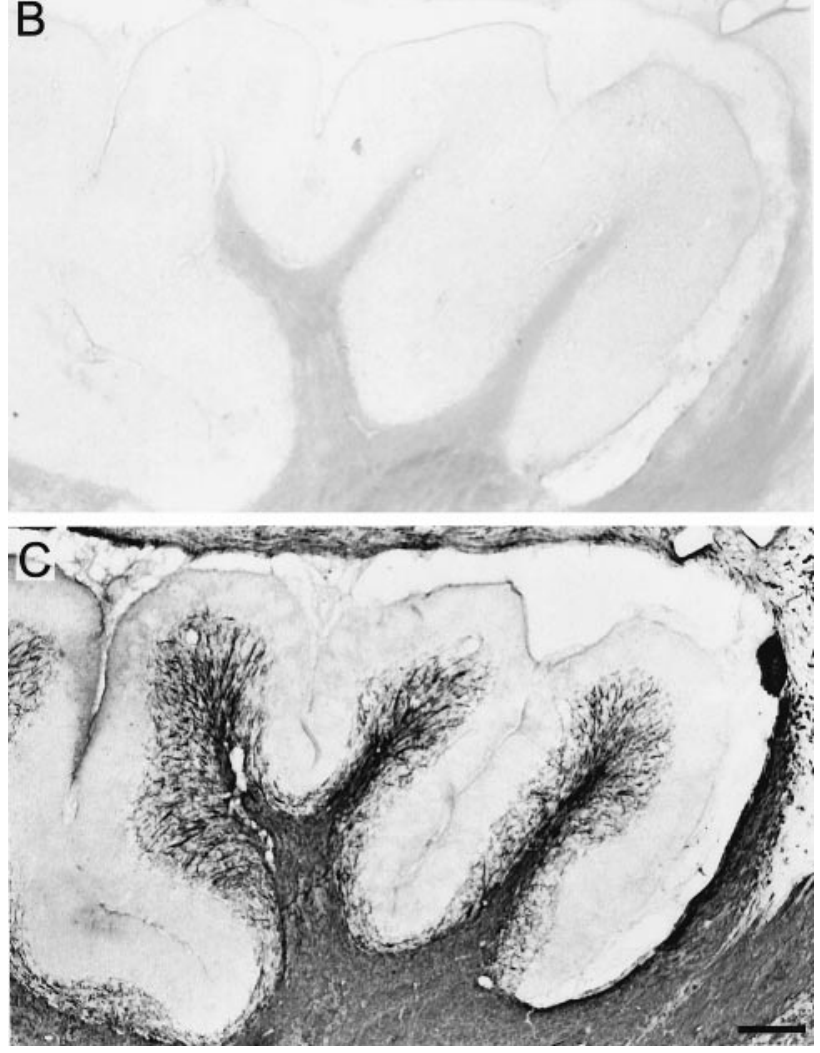

Figure 2. Anti-rMAL immunostaining of the cerebellar white matter can be competed. Immunoreactivity of rMAL in the adult rat cerebellum is restricted to myelinated axons and white matter as shown with affinitypurified rMAL antiserum $(A)$. Consecutive sections were incubated with the affinity-purified rMAL antiserum in the presence $0.25 \mu \mathrm{g} / \mu \mathrm{l}$ of the corresponding peptide, resulting in strongly reduced staining $(B)$. A monoclonal antibody to MBP stains the same myelinated areas as antirMAL $(C)$. Scale bar, $310 \mu \mathrm{m}$.

obtained in a postembedding immunostaining protocol, where permeabilization is hampered even more (data not shown). These electron microscopy results clearly demonstrate that rMAL protein is part of the compact myelin sheath of central and peripheral myelin.

\section{Localization of rMAL in kidney}

Earlier studies described the presence of rMAL transcripts in adult kidney (Kim et al., 1995; Schaeren-Wiemers et al., 1995b) and canine MAL has been isolated from MDCK cells (Zacchetti et al., 1995), but nothing was known about the developmental expression profile, the distribution, and the physiological role of the protein in vivo. A developmental analysis by Northern blot showed that rMAL mRNA is strongly expressed in the rat kidney at birth. A high expression level is maintained throughout development until adulthood (Fig. 5A). In situ hybridization with digoxigenin-labeled antisense RNA probes revealed the widespread presence of rMAL mRNA in defined parts of the kidney tubuli (Fig. $6 A$ ). In the kidney cortex, rMAL mRNA was detected in parts of the ascending distal tubuli. Counterstain with Hoechst dye showed that the glomeruli as well as the proximal tubuli were devoid of hybridization signal (Fig. 6B, arrows). Intense labeling was observed in kidney medullary layers on most tubular parts, including the loops of Henle. Highest levels of rMAL transcripts were found in the most distal parts of the tubuli and the collecting ducts (Fig. 6C, arrows). Incubation of adjacent sections with the digoxigenin-labeled sense RNA probe did not result in any signal (Fig. 6D).

Immunocytochemistry showed that $\mathrm{rMAL}$ protein was abundantly present in the adult kidney, in a pattern corresponding closely to that of the mRNA (Fig. 7A). Interestingly, and in contrast to the situation in myelin, relatively mild permeabilization conditions were sufficient to demonstrate the presence of rMAL protein, and harsh permeabilization treatment abolished rMAL staining. At birth, rMAL protein was already strongly expressed in the tubular parts (Fig. 7B). Semithin sections of epoxy resin-embedded material revealed that the immunoreactivity was localized mainly on the apical (luminal) side of the tubular cells (Fig. 7C). No detectable expression was seen on the basolateral membranes. Preembedding immunoelectron microscopy confirmed the localization of rMAL protein in the apical plasma membrane and in its typical microvilli (Fig. 7D, arrowheads). In accordance with the proposed extracellular localization of the peptide sequence used as antigen, the immunogold particles were localized mostly on the extracellular, luminal side of the plasma membranes.

\section{Localization of rMAL in stomach epithelium}

In the mouse, Northern blots have shown prominent transcript expression of MAL in the stomach (Magyar et al., 1997). By immunocytochemistry we found strong expression of rMAL protein in the glandular part of the rat stomach (Fig. $8 A, B$ ). Interestingly, rMAL protein was absent from the nonglandular part of the stomach epithelium, and the expression stopped abruptly at the transition zone between the two epithelia (Fig. $8 A$ ). As in the kidney, the protein in stomach was already strongly expressed at birth and in early postnatal stages and maintained at high levels up to the adult stage (Fig. $8 B$ ). Similar to the situation in the kidney, the expression of rMAL protein was strictly limited to the apical plasma membrane of the highly folded surface epithelium and the canaliculi of the glandular ducts (Fig. 8B, arrows and arrowhead, respectively).

\section{rMAL in spleen and thymus}

Only low levels of rMAL mRNA were detected in the rat spleen; Northern blots had to be exposed 10 times longer than necessary for myelinated tissue or kidney (Fig. 5B). The developmental profile showed expression at all ages, P0 to adult, whereby expression at P5 and P10 seemed slightly decreased. Relatively stronger expression was found in the juvenile (P25) and adult stages. By in situ hybridization, only a very weak signal in a moderate number of cells was detected in the red pulp of newborn and adult rat spleen (data not shown). The white pulp of the spleen was devoid of 

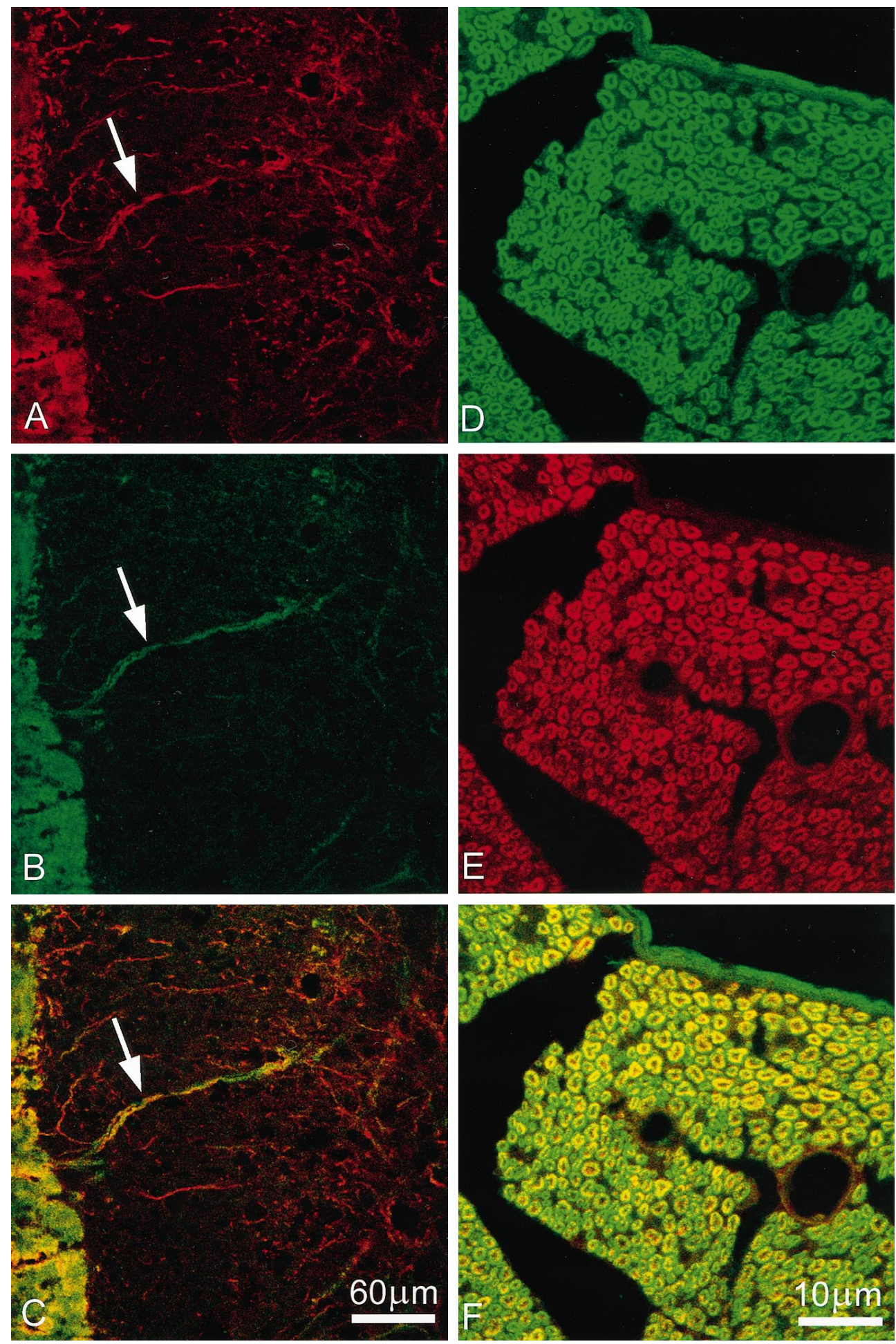

Figure 3. rMAL is colocalized with the structural myelin proteins PLP and MBP. Confocal immunofluorescence analysis of parts of P15 rat dorsal spinal cord $(A-C)$ and adult rat spinal root cross sections $(D-F)$ has been performed. Monoclonal anti-PLP antibody (TRITC-labeled secondary antibodies) stains myelin in white matter and around axons of the substantia gelatinosa $(A)$. Monoclonal anti-MBP antibody (FITC-labeled secondary antibodies) reveals the ring-like structures of myelin sheath around peripheral axons $(D)$. Nearly identical structures are labeled with the rMAL antiserum in the same sections $(\mathrm{B}, \mathrm{E})$, using the complementary FITClabeled $(B)$ or TRITC-labeled $(E)$ secondary antibodies. Double exposure demonstrates the colocalization of rMAL and PLP or MBP, respectively, resulting in orange/yellowish staining $(C, F)$. Differences in colocalization are likely caused by the lower abundance of rMAL as compared with MBP, the different permeabilization optima for these antigens, and the later developmental expression of rMAL protein in the CNS as compared with PLP (M. Frank, unpublished observations). Scale bars: $A-C$, $10 \mu \mathrm{m} ; D-F, 60 \mu \mathrm{m}$. detectable hybridization signals, suggesting T-cells as the signal source. rMAL protein levels in the spleen were below the detection limit of immunohistochemistry or immunofluorescence (data not shown). Although MAL mRNA could be detected in adult thymus in humans (Alonso and Weissman, 1987), MAL transcripts were not detectable in rat (data not shown).

\section{rMAL protein shows extraction properties of a proteolipid in myelin and kidney}

Proteolipids are highly hydrophobic proteins that are only soluble in organic solvents (classically a 2:1 mixture of chloroform/meth- anol) or in solutions containing strong detergents (Lees et al., 1979; Schlesinger, 1981). We isolated kidney and spinal cord plasma membranes as well as myelin membranes from P15 rats by sucrose density centrifugation. These membrane fractions were extracted with chloroform/methanol. The organic phase, which contains lipids and proteolipids, was collected and analyzed by SDS-PAGE and Western blot analysis using the anti-rMAL antibody. As shown in Figure $9 A$, rMAL protein was detected as an immunopositive band of $\sim 16 \mathrm{kDa}$ in kidney and myelin membranes. Thus, by partitioning into the organic phase, rMAL 


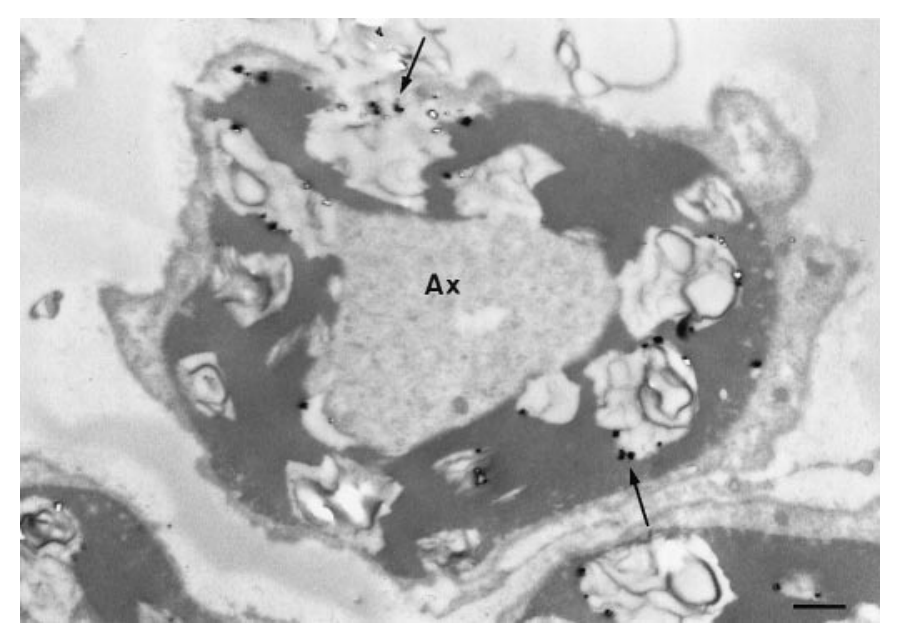

Figure 4. Electron microscopic section of heavily myelinated axons of a rat dorsal spinal root showing immunostaining for rMAL by gold-coupled secondary antibodies. Immunoelectron microscopy localizes rMAL to compact myelin. Silver-intensified gold grains are visible throughout the myelin sheath (arrow), especially at sites of myelin disruption during fixation and permeabilization. Scale bar, $0.5 \mu \mathrm{m}$.

behaves as a typical proteolipid. The major proteolipids of myelin, PLP and its splice variant DM-20, were also readily detected in the same fraction of myelin membrane material as immunobands of 27 and $23 \mathrm{kDa}$, respectively, when the blots were reprobed with an anti-PLP antibody (Fig. 9B); however, PLP and DM-20 were absent from the kidney. In silver-stained gels (Fig. $9 C$ ), an rMAL protein band of $16 \mathrm{kDa}$ in kidney (lane 6) and myelin fractions (lane 7) and PLP and DM-20 protein bands of 23 and $27 \mathrm{kDa}$ in myelin (lane 7) were visible. This indicates that rMAL, PLP, and DM-20 are the major proteolipids of CNS myelin. In the kidney, two unidentified major protein bands of 23 and $31 \mathrm{kDa}$ also were present. The $16 \mathrm{kDa}$ band of rMAL was not present in extracted heart plasma membranes (Fig. 9C, lane 5), but as in kidney, two unidentified proteolipids of 23 and $32 \mathrm{kDa}$ were visible.

\section{rMAL is part of detergent-insoluble glycosphingolipid- containing complexes in spinal cord and kidney}

The strong hydrophobicity of MAL and its specific localization in compact myelin and in apical membranes of epithelial cells, in which glycosphingolipids are specifically localized as well, suggest that this protein may interact with lipids in these membranes. Interactions of certain proteins with glycosphingolipids are known to result in the formation of detergent-insoluble proteinlipid microdomain complexes after detergent extraction at low temperature (Brown and Rose, 1992; Fiedler et al., 1993). We extracted kidney, spinal cord plasma membranes, and myelin with the detergent CHAPS $\left(1 \%\right.$ at $\left.4^{\circ} \mathrm{C}\right)$ and analyzed the presence of rMAL protein in CHAPS-soluble and CHAPS-insoluble fractions after chloroform/methanol extraction by Western blot analysis (Fig. 10). Corresponding fractions were analyzed for their lipid composition by TLC (Fig. 11). On Western blots, a single, strongly immunoreactive band of $16 \mathrm{kDa}$ was detected in CHAPS-insoluble fractions of kidney and spinal cord plasma membranes (Fig. 10A). The rMAL protein was highly enriched in the CHAPS-insoluble fractions, when compared with the CHAPS-soluble fractions (Fig. 10B, lanes 3-6). An immunopositive band of $16 \mathrm{kDa}$ was detected in the insoluble fraction, which was absent from the corresponding soluble (supernatant) fraction.

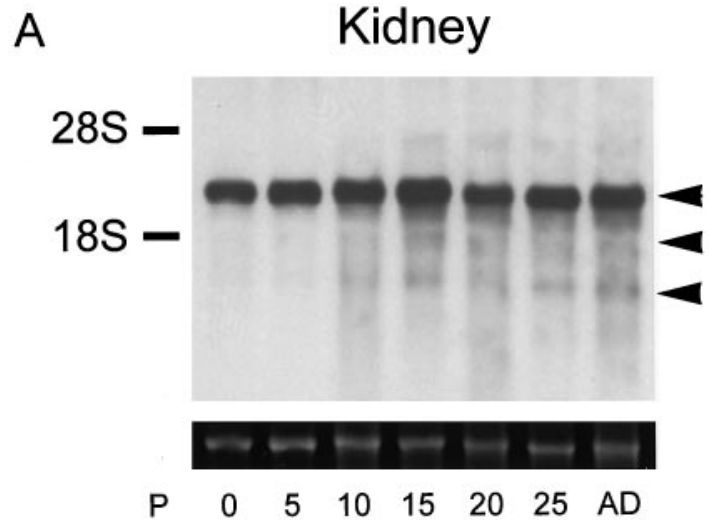

B Spleen

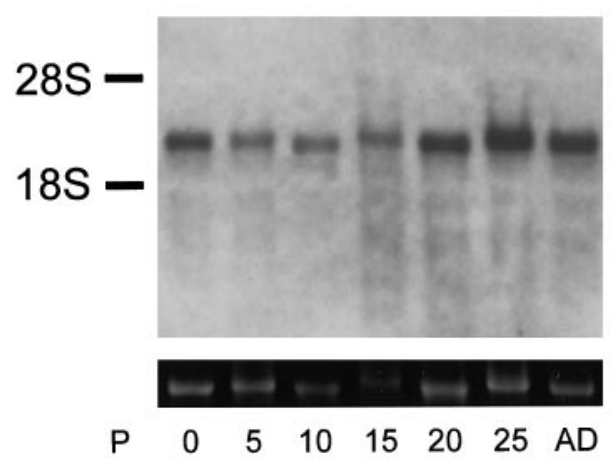

Figure 5. Developmental Northern analysis of rMAL in kidney and spleen. Total RNA ( $2 \mu \mathrm{g})$ obtained from rats at birth (P0), at P5, P10, P15, P20, and P25, and adult animals was separated on formaldehyde/agarose gels. The $2.2 \mathrm{~kb}$ rMAL transcript (arrowhead) is constitutively expressed in kidney $(A)$ and spleen $(B)$ after birth. However, expression of rMAL transcript is much weaker in spleen than in kidney because revealing the signal in spleen $(B)$ needs a 10 times longer exposure than for kidney $(A)$ (20 min instead of $2 \mathrm{~min}$ ). Two additional weak transcripts of $\sim 1.7$ and 1.2 $\mathrm{kb}$ (arrowhead) appear in postnatal and adult kidney, probably representing minor splice forms of the MAL transcript.

When CHAPS-insoluble material was analyzed on SDS-PAGE before chloroform/methanol extraction, multiple anti-rMALpositive immunobands were revealed on the Western blot from this gel (Fig. 10C, lane 7). A similar pattern was observed when the same blot was reprobed with the monoclonal antibody $\mathrm{O} 4$ (Fig. 10C, lane 8, arrows), which recognizes sulfatide (Sommer and Schachner, 1981; Bansal et al., 1989). Interestingly, both antibodies, anti-rMAL and O4, strongly stained a protein band of $\sim 18 \mathrm{kDa}$, whereas the $16 \mathrm{kDa}$ rMAL-positive band was only very weakly stained with $\mathrm{O} 4$. A molecular weight shift of $2 \mathrm{kDa}$ could correspond to a complex of one rMAL with two to five sulfatide molecules (molecular weight of sulfatide is $\sim 0.8 \mathrm{kDa}$, depending on the length of the fatty acid backbone of sulfatide). The bands of other molecular weight that stained for rMAL as well as O4/sulfatide may be multimers $(32,44 \mathrm{kDa})$ or a breakdown product $(12 \mathrm{kDa})$, respectively. When CHAPS-insoluble material was extracted with chloroform/methanol and run on the same gel as a control, only the $16 \mathrm{kDa}$ rMAL immunoband was detected (Fig. 10C, lane 9). Subsequent staining of this lane with the $\mathrm{O} 4$ antibody did not give an immunopositive signal (Fig. 10C, lane 10), demonstrating that rMAL protein alone is not recognized by the anti-sulfatide antibody. Similarly, in blotted CHAPS-soluble 

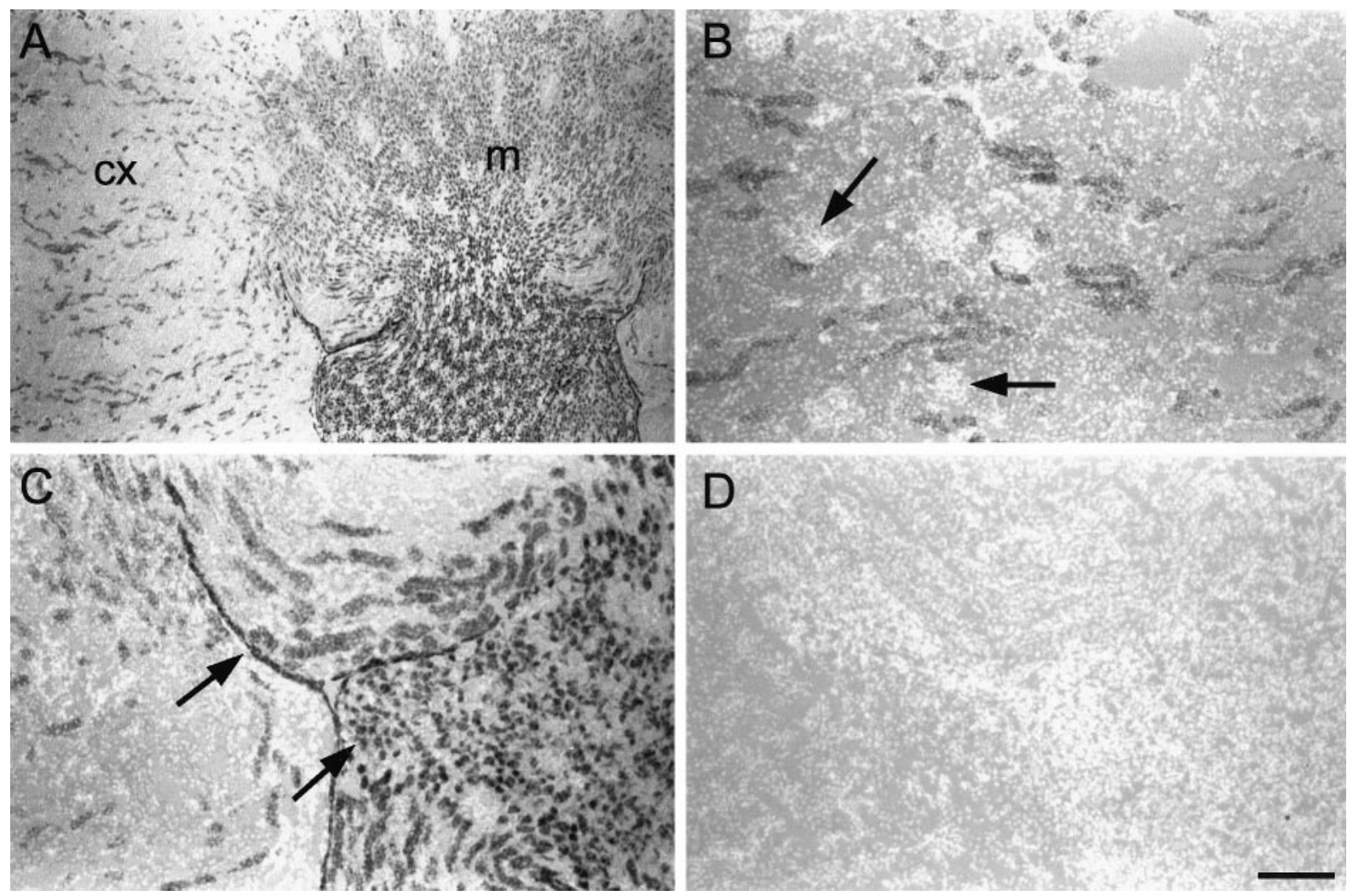

Figure 6. Epithelial cells of distal kidney tubuli express rMAL transcript. In situ hybridization on consecutive cross sections of an adult rat kidney was performed for rMAL with digoxigenin-labeled antisense riboprobes $(A-C)$. Low magnification of a bright-field micrograph shows a widespread expression of rMAL transcript in kidney cortex $(c x)$ and medulla $(m)(A)$. For sections shown in $B-D$, bright-field and fluorescence illumination were combined to visualize kidney cytoarchitecture by counterstain with the Hoechst nuclear dye. The hybridization signal in kidney cortex $(B)$ is localized to cells of the ascending tubuli. The glomeruli (arrow) are devoid of MAL signals. In the kidney medulla $(C)$ strong hybridization signals are seen on distal kidney tubuli and collecting ducts (arrows). No hybridization signals were detected on consecutive sections treated with sense riboprobe $(D)$. Scale bar (shown in $D$ ): $A, 500 \mu \mathrm{m} ; B-D, 130 \mu \mathrm{m}$.

(supernatant) material (before chloroform/methanol extraction), bands of 16 or $18 \mathrm{kDa}$ immunoreactive with rMAL and $\mathrm{O} 4$ antibodies were absent (data not shown).

For lipids analysis, CHAPS-insoluble and CHAPS-soluble fractions from kidney (Fig. 11A) and spinal cord (Fig. 11B) plasma membranes were extracted with chloroform/methanol and run on TLC to compare the relative content of glycolipids with that of phospholipids in these fractions. The identity of lipids was determined by comparison with commercial standards run in parallel on the same TLC (lane S) and by two successive staining protocols. First, total lipids were stained by incubation of the TLC with iodide vapor (Fig. 11, lanes $S, 1$, and 2, respectively). This was followed by incubation of the TLC with orcinol, which specifically stains glycolipids purple. Because of the incubation at high temperature that is necessary for development of the orcinol stain, the phospholipids are charred and appear as brown spots, indistinguishable from the glycolipid spots in Figure 11 (lanes 3 and 4, respectively). In the CHAPS-insoluble fractions from both kidney and spinal cord, an apparent enrichment of the glycosphingolipids galactosylceramide and sulfatide over the phospholipids phosphatidyl-choline, phosphatidyl-ethanolamine, and sphingomyelin was observed. The samples were loaded such that the sulfatide content in the CHAPS-soluble and CHAPSinsoluble fraction is equal. In kidney, a single galactosylceramide band is visible only in the CHAPS-insoluble fraction and is absent from the soluble fraction (Fig. 11A, lane 3 and 4). In spinal cord, more galactosylceramide is present than in kidney. The double band corresponds to galactosylceramides with different fatty acid residues: in the top band galactosylceramides with nonhydroxy fatty acid chains are present, whereas the bottom band represents galactosylceramides with $\alpha$-hydroxy fatty acids (Fig. 11B, lanes 3 and 4 ). Note that in both tissues larger quantities of the phospholipids, visible as more intensely stained bands, are present in the CHAPS-soluble fractions (Fig. 11, lanes 2 and 4 , respectively).

\section{DISCUSSION}

MAL transcripts and proteins have been independently isolated from several different cell types, including oligodendrocytes, the MDCK kidney cell line, and T-cell lines (Alonso and Weissman, 1987; Kim et al., 1995; Schaeren-Wiemers et al., 1995a; Zacchetti et al., 1995). Recombinant expression of the protein in cell lines in vitro suggested functions of MAL proteins in sorting, transport, and vesicle formation (Zacchetti et al., 1995; Puertollano et al., 1997). However, so far little was known about the distribution and possible function of the MAL protein in vivo. We found that rMAL protein is expressed in the compact myelin of PNS and CNS and on apical membranes of kidney and stomach epithelial cells.

By using an affinity-purified antibody in confocal imaging we could demonstrate that rMAL protein is localized throughout the myelin spiral with a high degree of colocalization with the struc- 


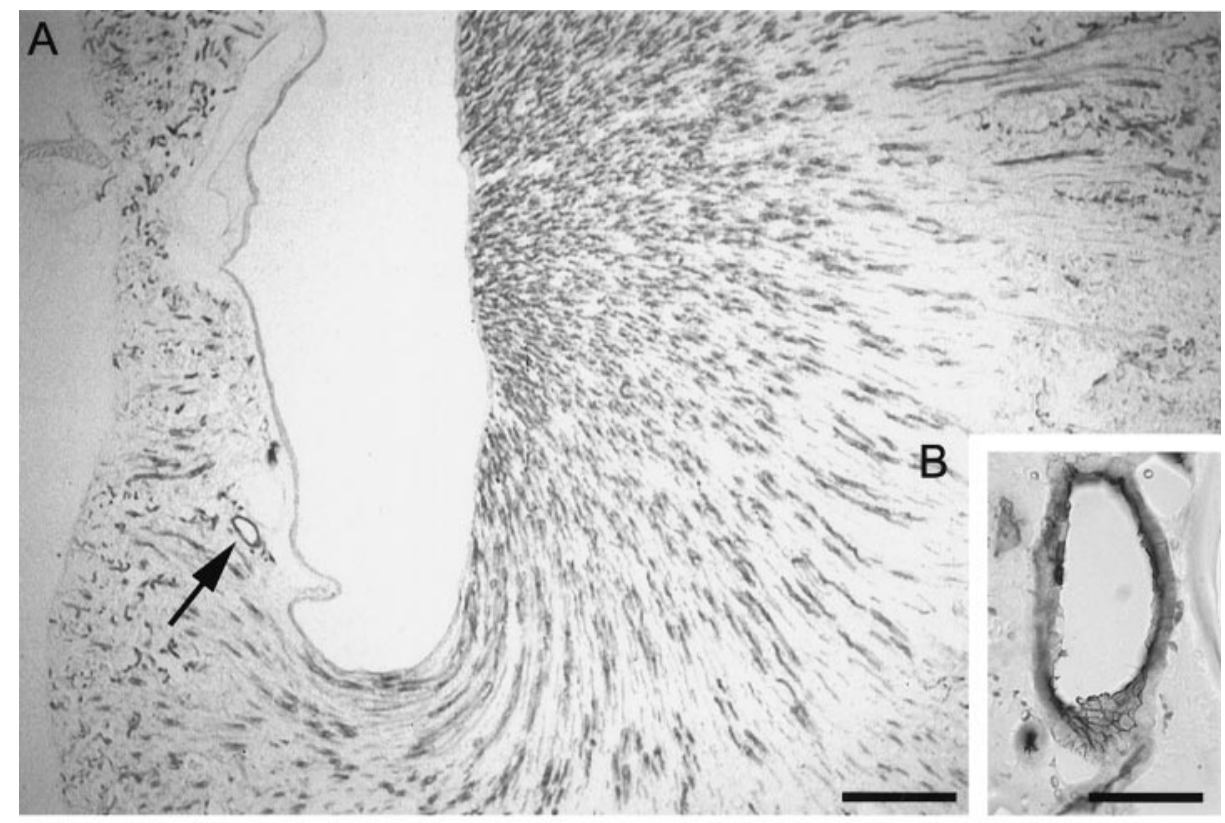

Figure 7. Immunostaining of $\mathrm{rMAL}$ protein in the kidney, visualized using the $\mathrm{ABC}$ method with DAB as a chromogen $(A-C$, bright-field micrographs) or with gold-coupled secondary antibodies ( $D$, electron micrograph). rMAL protein is strongly expressed on apical membranes of kidney tubuli. Widespread immunoreactivity in kidney tubuli is seen on the transverse section of a $\mathrm{P} 9$ rat kidney $(A)$. Higher magnification of a collecting duct branch (arrow) shows that the immunosignal is localized at the luminal (apical) pole of the duct cells $(B)$. Semithin sections $(0.5 \mu \mathrm{m})$ of a P12 kidney confirm the apical localization of rMAL in distal tubuli (arrow), whereas other kidney tubuli and connecting tissue (arrowheads) are devoid of staining $(C)$. Electron micrograph of distal tubulus cells from a P12 rat kidney labeled for rMAL with $10 \mathrm{~nm}$ immunogold $(D)$. Gold grains are found mainly on the apical plasma membrane and its microvilli emerging from the membrane (arrowheads). Most grains lie on the extracellular aspect of the plasma membrane, indicating that the corresponding epitope faces the extracellular space. Scale bars: $A, 350 \mu \mathrm{m} ; B, 60 \mu \mathrm{m} ; C$, $9 \mu \mathrm{m} ; D, 0.25 \mu \mathrm{m}$.
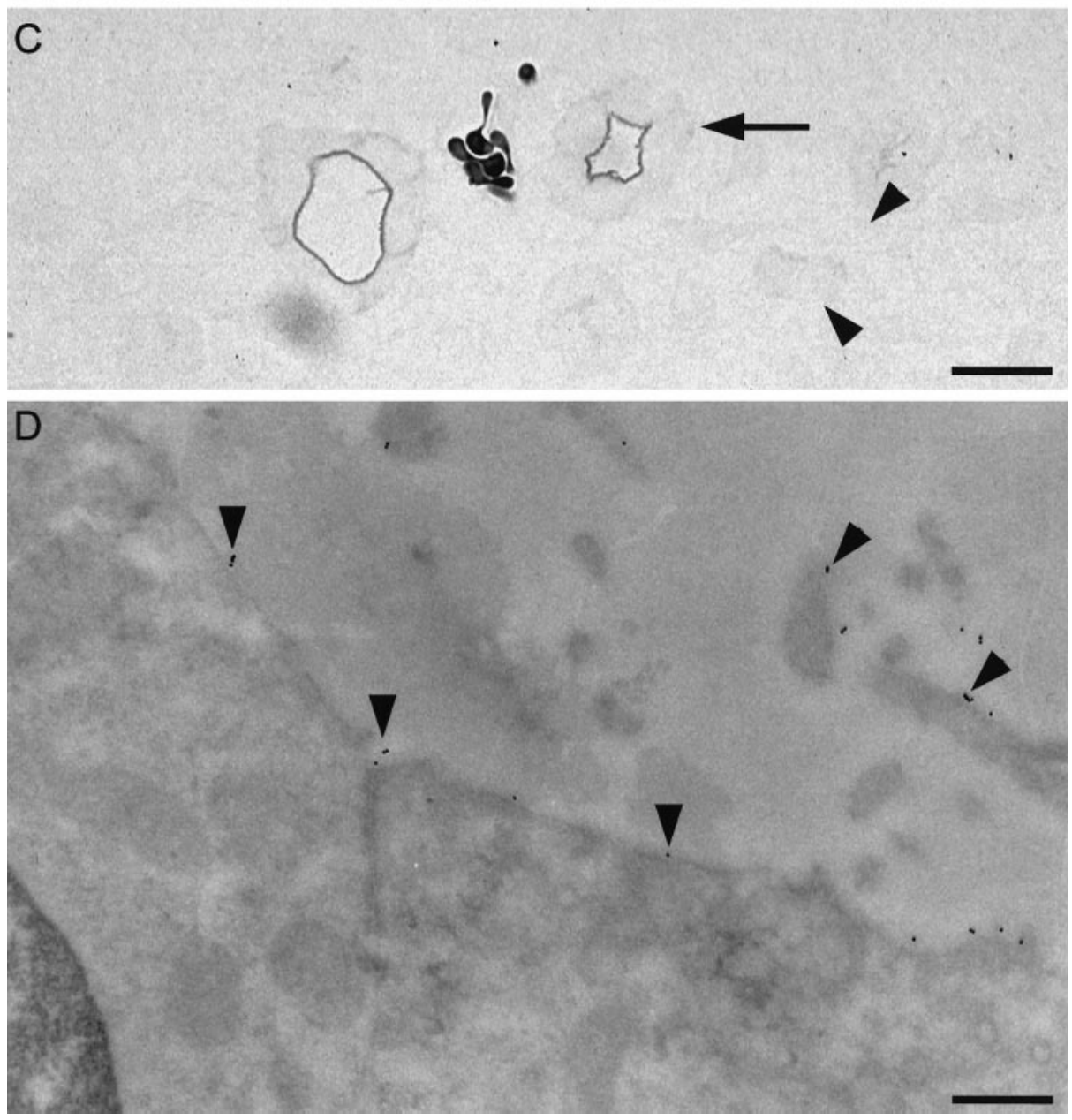

tural myelin proteins PLP and MBP, in both CNS and PNS myelin. Immunoelectron microscopy confirmed the localization of rMAL in compact myelin. This localization differs from that of connexin 32 and CD9, other 4TM proteins that are present in myelin, which are restricted in localization to specific sites of the myelin sheath. Connexin 32 is found at the paranodal regions and in the Schmidt-Lantermann incisures of the PNS (Scherer et al., 1995), whereas CD9 is localized at the outermost surface of the myelin spiral (Nakamura et al., 1996). The localization profile of rMAL resembles that of the 4TM proteins PLP and PMP22, which are predominantly distributed in compact myelin (Nave and Milner, 1989; Snipes et al., 1992). We conclude that rMAL is 

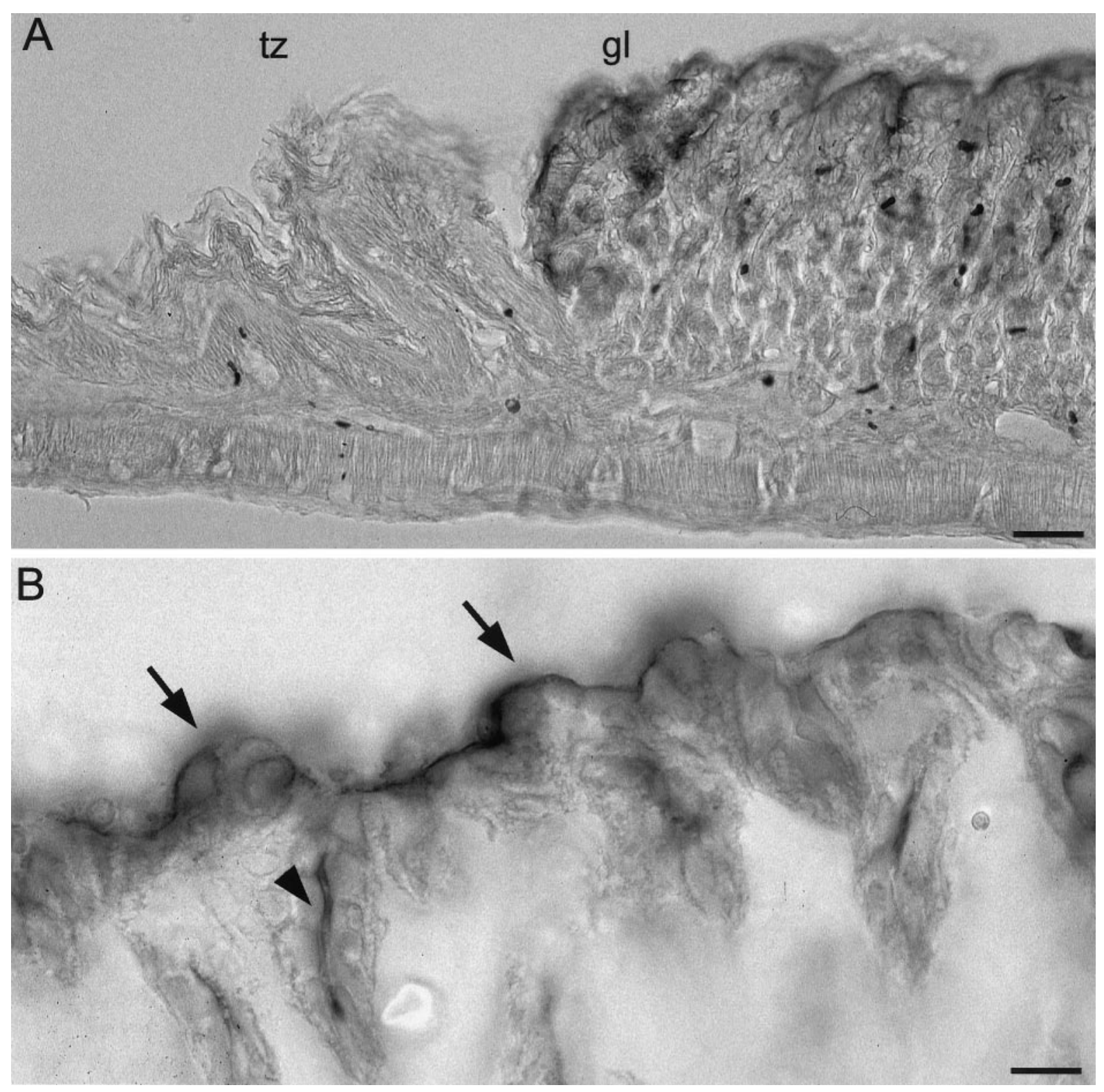

Figure 8. rMAL protein is present on apical membranes of glandular stomach epithelium. Immunostaining for rMAL protein was performed in the rat stomach of a P6 $(A)$ and an adult animal $(B)$. rMAL protein localization is strictly limited to the glandular part of stomach epithelium $(g l)$ but is absent from the nonglandular part [transition zone $(t z)](A)$. As in the kidney, the immunoreactivity is mainly localized to the apical part of the plasma membrane $(B$, arrows $)$, deeply folded to canaliculi of stomach glands ( $B$, arrowhead). Scale bars: $A, 45 \mu \mathrm{m} ; B, 14 \mu \mathrm{m}$.

a structural protein in compact myelin rather than a pore- or channel-forming protein. The presence of the MAL protein in compact myelin and the harsh permeabilization required for immunohistochemistry are in line with the biochemical data showing that MAL is a proteolipid and tightly associated with the major glycosphingolipids of the myelin sheath.

In the kidney, a function of MAL as part of an ion channel, pore, or transporter would seem more conceivable. However, the widespread distribution found over all the distal tubular segments could argue against this possibility; these segments differ widely in morphology and function (for review, see Kaissling and Kriz, 1992). Therefore, a more general role of MAL protein in these epithelial cells seems plausible. In the rat kidney, MAL protein was highly enriched in the apical (luminal) membranes of the tubular epithelial cells. Previously, canine MAL (VIP17) has been isolated from apical transport vesicles of MDCK cells, and the tagged recombinant protein was preferentially localized in vesicular structures near the apical cell membrane of transfected MDCK cell in vitro (Zacchetti et al., 1995). In addition to the suggested role of MAL as a constituent of the intracellular sorting and transport machinery (Zacchetti et al., 1995), MAL may function as a structural protein in the apical membranes of specialized epithelia such as kidney tubuli and stomach. In vivo, rMAL is highly enriched at the apical cell membranes but is present in minor amounts in vesicular structures within the kidney cell cytosol, in contrast to the findings in various cell lines expressing recombinant MAL (Rancano et al., 1994; Zacchetti et al., 1995). A function of MAL protein in sorting and transport might be more important during development, for example in myelin formation and kidney organogenesis. 


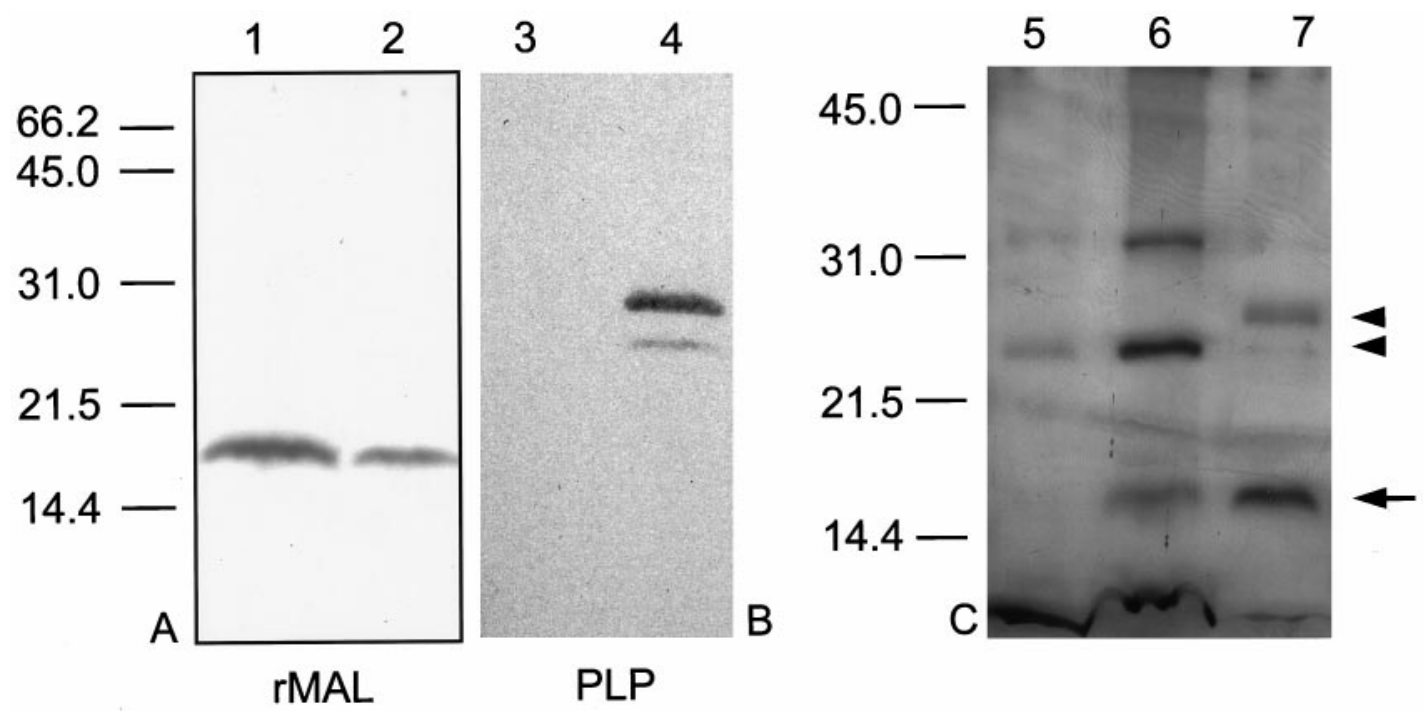

Figure 9. rMAL protein is a proteolipid of myelin and kidney. A, An immunoreactive band of $16 \mathrm{kDa}$ is seen on a Western blot of chloroform/ methanol-soluble material extracted from kidney plasma membranes (lane 1) and myelin (lane 2). B, The same Western blot was reprobed with a monoclonal PLP antibody revealing the presence of PLP $(27 \mathrm{kDa})$ and DM $20(23 \mathrm{kDa})$, the two major proteolipids in myelin (lane 4$)$ but not in kidney (lane 3). C, Silver-stained protein gel of chloroform/methanol-extracted plasma membranes shows the $16 \mathrm{kDa}$ rMAL protein band (arrow) in myelin (lane 7) and in kidney (lane 6) but not in heart (lane 5). The proteolipids PLP and DM 20 are visible in CNS myelin (arrowheads). Two unidentified proteolipids are present in heart and kidney at 24 and $32 \mathrm{kDa}$, respectively.

Biochemically, MAL is a proteolipid that forms detergentinsoluble complexes and is associated with glycosphingolipids in myelin and kidney. Detergent insolubility of proteins is thought to be caused by association of the protein with a glycosphingolipid microenvironment (Simons and van Meer, 1988; Brown and Rose, 1992). Some care has to be taken with the interpretation of association of membrane components after detergent extraction. For example, a redistribution of GPI-anchored proteins and sphingolipids into caveolae has been reported after application of detergent (Mayor et al., 1994; Fujimoto, 1996). Several lines of investigation support the idea that detergent-resistant membrane domains are not detergent-induced artifacts but exist as domains in the cell membrane (for review, see Brown and London, 1997; Simons and Ikonen, 1997).

Our in vivo findings confirm earlier observations in MDCK cells, in cultured oligodendrocytes (Kim et al., 1995; Zacchetti et al., 1995), and in cells expressing recombinant MAL protein (Millan et al., 1997a,b). It has been proposed that association and sorting of specific apical membrane proteins with glycosphingolipids takes place in the trans-Golgi network; caveolin (VIP 21) and MAL/VIP17 are such proteins obtained from these detergent-insoluble complexes (Fiedler et al., 1993; Zacchetti et al., 1995). Our Western blot analysis suggests that rMAL might be complexed with sulfatide in a way that withstands reducing SDS-PAGE conditions. Larger sulfatide-containing multimers are also present.

Many apical membranes of epithelia, including kidney and stomach, are known to be highly enriched in glycosphingolipids, e.g., galactosylceramide and sulfatide (Simons and van Meer, 1988; Shayman and Radin, 1991; Lande et al., 1994). A similar enrichment in these glycosphingolipids, in particular galactosylceramide and sulfatide, has been shown for myelin membranes of the CNS and PNS (Morell, 1984). Thus, the surface of the oligodendrocyte membrane, which wraps around the axon and forms the myelin sheath, has been referred to as the apical membrane in analogy to the situation in epithelial cells (for review, see Pfeiffer et al., 1993). The close association of MAL with specific glycosphingolipids, and their localization in compact myelin and in the apical membranes of kidney tubuli and stomach, strongly suggests that MAL could fulfill structural functions in these membranes by stabilizing and maintaining glycosphingolipid microdomains, in addition to its possible role in sorting and intracellular transport.

Two functional aspects are shared by myelin and apical membranes of stomach and kidney epithelium: (1) the high degree of local membrane curvature (myelin wraps or microvilli extrusions) and (2) the high impermeability for water and small molecules. It is thought that these features are mediated by glycosphingolipids. Glycosphingolipids are mainly present in the exoplasmic leaflet of the lipid bilayer, whereas phospholipids are enriched in the endoplasmic leaflet (Simons and van Meer, 1988; van Meer, 1989). This lipid asymmetry could induce bilayer curvature by interaction of glycosphingolipids with membrane proteins and by the physical properties (e.g., size and fatty acid backbone) of the glycosphingolipids, as has been shown in model membranes $(\mathrm{Cu}-$ ratolo and Neuringer, 1986). The observation that the lipids of the exoplasmic leaflet, glycosphingolipids and other sphingolipids, are essential determinants of the membrane permeability properties has recently been shown for stomach and kidney epithelia with regard to tightness for water and protons (Lande et al., 1994). The important contributions of glycosphingolipids to the insulating properties of myelin membranes were demonstrated in recent studies of knock-out mice for the enzyme uridine diphosphate galactose:ceramide galactosyltransferase (Bosio et al., 1996; Coetzee et al., 1996). The lack of this key enzyme in the synthesis pathway of galactosylceramide and sulfatide leads to a dramatic decrease of nerve conduction velocity, probably by impairment of the saltatory impulse conduction. The organization and stable integration of these specific lipids in the membranes of myelin and epithelial cells is probably controlled by interactions with specific structural proteins. We hypothesize that MAL protein is an important component of this process. 

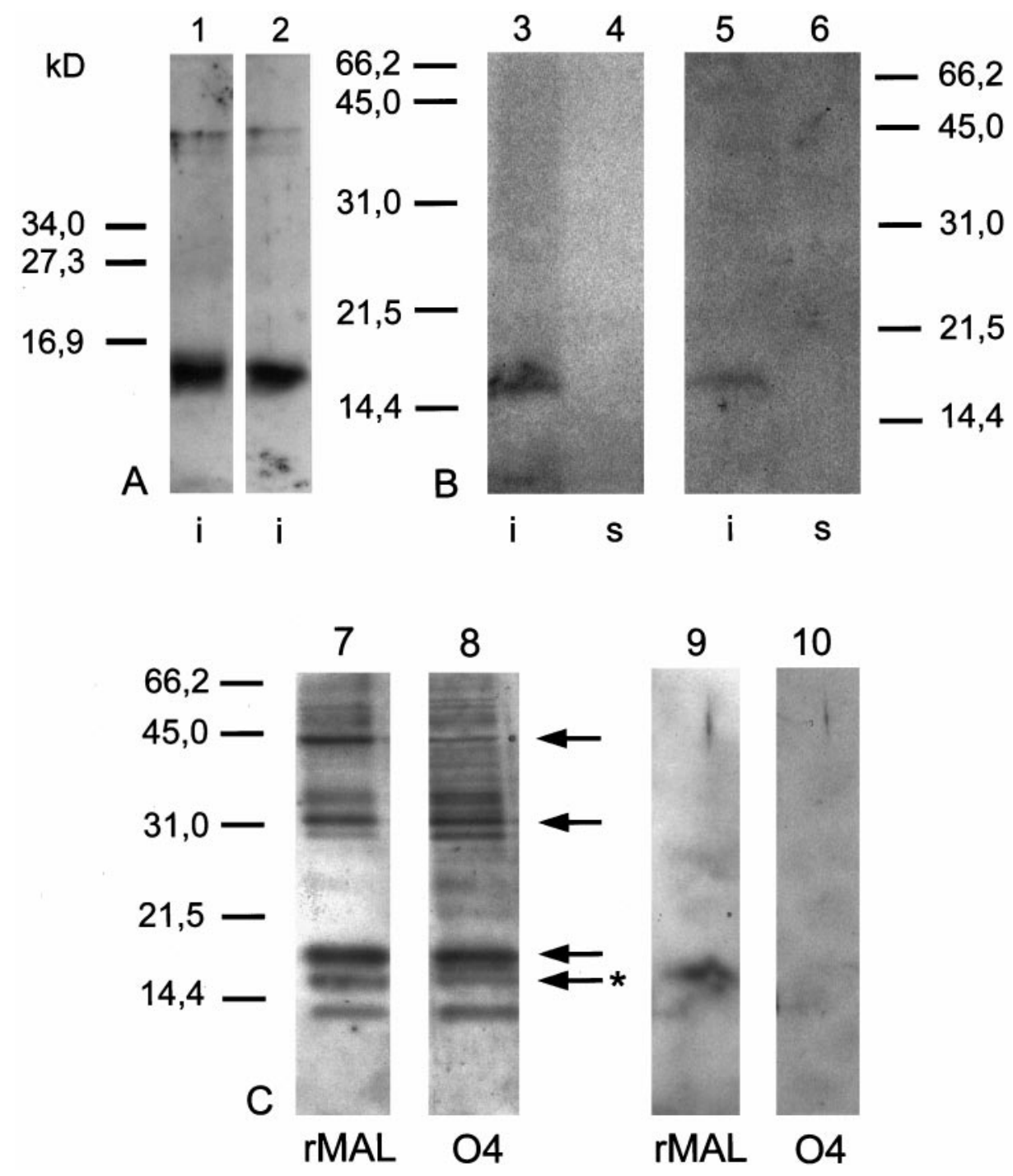

Figure 10. rMAL is associated with glycosphingolipids in CHAPS-insoluble complexes. $A$, Western blot of CHAPS-insoluble $(i)$ material separated with SDS-PAGE after chloroform/methanol extraction from kidney (lane 1) and spinal cord plasma membranes (lane 2). The rMAL protein is detected as a $16 \mathrm{kDa}$ immunopositive band in both tissues. $B$, Equal amounts of protein $(3 \mu \mathrm{g})$ of CHAPS-insoluble $(i)$ and CHAPS-soluble $(s)$ fraction were analyzed after chloroform/methanol extraction by SDS-PAGE followed by Western blot. Although rMAL is clearly detected as the $16 \mathrm{kDa}$ immunopositive band in the CHAPS-insoluble material ( $i$ ), it is absent in the corresponding CHAPS-soluble material $(s)$ of kidney (lanes 3 and 4 ) and spinal cord (lanes 5 and 6 ) plasma membranes. $C$, Western blot of CHAPS-insoluble material from kidney $(5 \mu \mathrm{g})$ without previous chloroform/methanol extraction. A strongly immunopositive band of $18 \mathrm{kDa}$ and bands at 12, 32, and $44 \mathrm{kDa}$ are recognized by the anti-rMAL antibody (lane 7, arrows). The monoclonal anti-sulfatide antibody $\mathrm{O} 4$ reveals a nearly identical pattern, when the same blot is reprobed (lane 8, arrows). The major difference is that the expected immunopositive band of $16 \mathrm{kDa}$ (arrow with asterisk) is strongly recognized by the anti-rMAL antibody but only weakly by the O4 antibody. This suggests a shift of $\sim 2 \mathrm{kDa}$ for the $18 \mathrm{kDa}$ band, which could be caused by complexation of rMAL with sulfatide molecules. When the same material was extracted with chloroform/methanol and run in a parallel lane as a control, only the $16 \mathrm{kDa}$ band was immunopositive for rMAL (lane 9). This band did not react with $\mathrm{O} 4$ antibody after reprobing of the same lane (lane 10).

Besides MAL, the 4TM protein plasmolipin is known to be localized in myelin and apical kidney membranes, but its function is currently unknown (Fischer et al., 1994; Gillen et al., 1996). Similar to MAL, plasmolipin is a proteolipid, but the solubilization properties in CHAPS or Triton X-100 were not tested yet. Plasmolipin has been found as a constituent of clathrin-coated vesicles obtained from CNS white matter (Sapirstein et al., 1992). Very recently, both proteins, MAL and plasmolipin, were grouped together in a family on the basis of a conserved, shared amino acid motif (Magyar et al., 1997; Perez et al., 1997).

The MAL gene was first isolated from human T-cell lines (Alonso and Weissman, 1987), and the presence of MAL transcripts was reported in human thymus (Rancano et al., 1994).
Similarly, the 4TM protein CD9 was discovered as a surface protein of hematopoetic and myelinating cells and has been shown to play a role in cell adhesion in both cell types (Hadjiargyrou et al., 1996). In the rat we have found low rMAL transcript levels in spleen, probably only in T-cell subpopulations; however, we did not detect any transcripts in thymus. Recently, upregulation of MAL mRNA was found after treatment with interleukin 11 in human umbilical cord lymphocytes (Ireland et al., 1996). Sphingolipids and their metabolites are known to be involved in cell signaling in lymphocytes (Ballou, 1992; Brown, 1993), and MAL could be involved directly or indirectly in these processes too.

In conclusion, we have localized the proteolipid rMAL to specialized membranes of such diverse tissues as nervous system, 
A

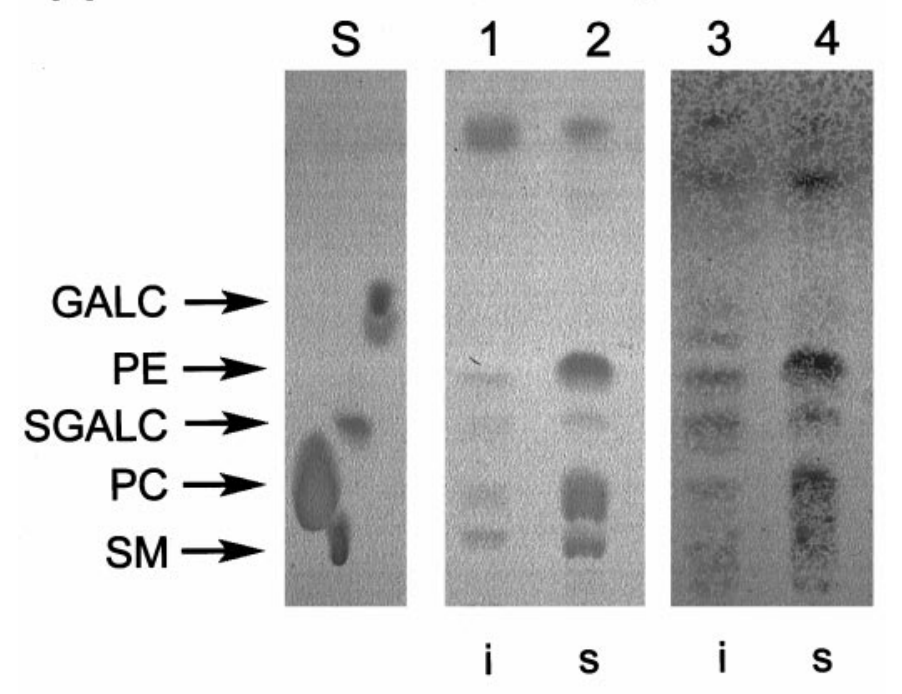

B

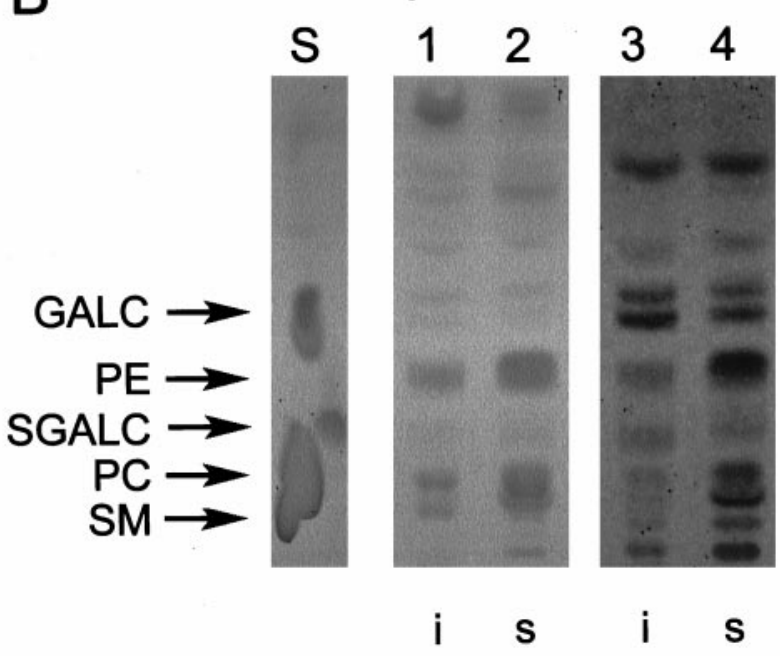

Figure 11. Glycosphingolipids are enriched in the CHAPS-insoluble fractions. Lipids in the CHAPS-insoluble $(i)$ and CHAPS-soluble fraction $(s)$ isolated from kidney $(A)$ and spinal cord plasma membranes $(B)$ were analyzed on TLC. Total lipids were visualized by iodide vapor (lanes 1 and 2, respectively); glycolipids were detected by subsequent staining of the same TLC with orcinol spray (see Results) (lanes 3 and 4, respectively). For comparison, the samples were loaded such that the sulfatide contents in the CHAPS-soluble and CHAPS-insoluble fractions were equal. A relative enrichment of galactosylceramide $(G A L C)$ and sulfatide ( $S G A L C)$ over phospholipids in the CHAPS-insoluble fractions of kidney and spinal cord (containing also the rMAL protein) is visible ( $A$ and $B$, lanes 1 and 3) when compared with the CHAPS-soluble fractions, where the phospholipids phosphatidyl-ethanolamine $(P E)$ and phosphatidylcholine $(P C)$ and sphingomyelin $(S M)$ are the main lipids present $(A$ and $B$, lanes 2 and 4$)$. Note that in kidney, galactosylceramide is only detectable with orcinol in the CHAPS-insoluble fraction but is virtually absent from the CHAPS-soluble fraction. In spinal cord, much more galactosylceramide is present. The double band represents two forms of GALC that differ in their fatty acid backbone length. The identity of the lipids was verified by comparison with commercial standards run in parallel on the same TLC (lanes $S, 50 \mu \mathrm{g}$ each). SM, Sphingomyelin; GALC, galactosylceramide; $S G A L C$, sulfatide; $P C$, phosphatidylcholine. kidney, and stomach. These membranes share a high glycosphingolipid content, and MAL is associated with these glycosphingolipids in vivo. In addition to a role of MAL in sorting and transport as suggested previously from in vitro work, we propose a function for MAL in the generation of specific membrane properties, e.g., impermeability for small molecules and local membrane curvature, by formation of protein-glycosphingolipid microdomains in myelin and apical membranes of epithelia.

\section{REFERENCES}

Alonso MA, Weissman SM (1987) cDNA cloning and sequence of MAL, a hydrophobic protein associated with human T-cell differentiation. Proc Natl Acad Sci USA 84:1997-2001.

Ballou LR (1992) Sphingolipids and cell function. Immunol Today 13:339-341.

Bansal R, Warrington AE, Gard AL, Ranscht B, Pfeiffer SE (1989) Multiple and novel specificities of monoclonal antibodies O1, O4, and $\mathrm{R}-\mathrm{mAb}$ used in the analysis of oligodendrocyte development. J Neurosci Res 24:548-557.

Bennett MV, Barrio LC, Bargiello TA, Spray DC, Hertzberg E, Saez JC (1991) Gap junctions: new tools, new answers, new questions. Neuron 6:305-320.

Bosio A, Binczek E, Stoffel W (1996) Functional breakdown of the lipid bilayer of the myelin membrane in central and peripheral nervous system by disrupted galactocerebroside synthesis. Proc Natl Acad Sci USA 93:13280-13285.

Brown D (1993) The tyrosine kinase connection: how GPI-anchored proteins activate T cells. Curr Opin Immunol 5:349-354.

Brown DA, London E (1997) Structure of detergent-resistant membrane domains: does phase separation occur in biological membranes? Biochem Biophys Res Commun 240:1-7.

Brown DA, Rose JK (1992) Sorting of GPI-anchored proteins to glycolipid-enriched membrane subdomains during transport to the apical cell surface. Cell 68:533-544.

Coetzee T, Fujita N, Dupree J, Shi R, Blight A, Suzuki K, Popko B (1996) Myelination in the absence of galactocerebroside and sulfatide: normal structure with abnormal function and regional instability. Cell $86: 209-219$.

Curatolo W, Neuringer LJ (1986) The effects of cerebrosides on model membrane shape. J Biol Chem 261:17177-17182.

Davis S, Aldrich TH, Valenzuela DM, Wong VV, Furth ME, Squinto SP, Yancopoulos GD (1991) The receptor for ciliary neurotrophic factor. Science 253:59-63.

Dermietzel R, Spray DC (1993) Gap junctions in the brain: where, what type, how many and why? Trends Neurosci 16:186-192.

Fiedler K, Kobayashi T, Kurzchalia TV, Simons K (1993) Glycosphingolipid-enriched, detergent-insoluble complexes in protein sorting in epithelial cells. Biochemistry 32:6365-6373.

Fischer I, Durrie R, Sapirstein VS (1994) Plasmolipin: the other myelin proteolipid. A review of studies on its structure, expression, and function. Neurochem Res 19:959-966.

Fujimoto T (1996) GPI-anchored proteins, glycosphingolipids, and sphingomyelin are sequestered to caveolae only after crosslinking. J Histochem Cytochem 44:929-941.

Gillen C, Gleichmann M, Greiner-Petter R, Zoidl G, Kupfer S, Bosse F, Auer J, Muller HW (1996) Full-length cloning, expression and cellular localization of rat plasmolipin mRNA, a proteolipid of PNS and CNS. Eur J Neurosci 8:405-414.

Hadjiargyrou M, Kaprielian Z, Kato N, Patterson PH (1996) Association of the tetraspan protein CD9 with integrins on the surface of S-16 Schwann cells. J Neurochem 67:2505-2513.

Harlow E, Lane DP (1988) Antibodies. A laboratory manual. Cold Spring Harbor, NY: Cold Spring Harbor Laboratory.

Ireland RC, Iovene C, Wagner EF, McInnis R, Oblon D, Alonso MA, Paul SR (1996) Use of messenger RNA differential display to identify interleukin-11-responsive genes in human umbilical cord blood mononuclear cells: IL-11 upregulates the expression of the hMAL gene. J Interferon Cytokine Res 16:829-834.

Kaissling B, Kriz W (1992) Morphology of the loop of Henle, distal tubule, and collecting duct. In: Handbook of physiology, Ed 2 (Windhagen EE, ed), pp 109-167. New York: American Physiological Society. Kaprielian Z, Cho KO, Hadjiargyrou M, Patterson PH (1995) CD9, a 
major platelet cell surface glycoprotein, is an ROCA antigen and is expressed in the nervous system. J Neurosci 15:562-573.

Kawaga T, Mekada E, Shishido Y, Ikenaka K (1997) Immune systemrelated CD9 is expressed in mouse central nervous system myelin at a very late stage of myelination. J Neurosci Res 50:312-320.

Kiguchi K, Henning-Chubb CB, Huberman E (1990) Glycosphingolipid patterns of peripheral blood lymphocytes, monocytes, and granulocytes are cell specific. J Biochem (Tokyo) 107:8-14.

Kim T, Fiedler K, Madison DL, Krueger WH, Pfeiffer SE (1995) Cloning and characterization of MVP17: a developmentally regulated myelin protein in oligodendrocytes. J Neurosci Res 42:413-422.

Lande MB, Priver NA, Zeidel ML (1994) Determinants of apical membrane permeabilities of barrier epithelia. Am J Physiol 267:C367-374.

Lees MB, Sakura JD, Sapirstein VS, Curatolo W (1979) Structure and function of proteolipids in myelin and non-myelin membranes. Biochim Biophys Acta 559:209-230.

Magyar JP, Ebensperger C, Schaeren-Wiemers N, Suter U (1997) Myelin and lymphocyte protein (MAL/MVP17/VIP17) and plasmolipin are members of an extended gene family. Gene 189:269-275.

Mayor S, Rothberg KG, Maxfield FR (1994) Sequestration of GPIanchored proteins in caveolae triggered by cross linking. Science 264:1948-1951.

Millan J, Puertollano R, Fan L, Alonso MA (1997a) Caveolin and MAL, two protein components of internal detergent-insoluble membranes, are in distinct lipid microenvironments in MDCK cells. Biochem Biophys Res Commun 233:707-712.

Millan J, Puertollano R, Fan L, Rancano C, Alonso MA (1997b) The MAL proteolipid is a component of the detergent-insoluble membrane subdomains of human T-lymphocytes. Biochem J 321:247-252.

Morell P (1984) Myelin, Ed 2. New York: Plenum.

Nakamura Y, Iwamoto R, Mekada E (1996) Expression and distribution of CD9 in myelin of central and peripheral nervous systems. Am J Pathol 149:575-583.

Nave KA (1994) Neurological mouse mutants and the genes of myelin. J Neurosci Res 38:607-612.

Nave KA, Milner RJ (1989) Proteolipid proteins: structure and genetic expression in normal and myelin-deficient mutant mice. Crit Rev Neurobiol 5:65-91.

Perez P, Puertollano R, Alonso MA (1997) Structural and biochemical similarities reveal a family of proteins related to the MAL proteolipid, a component of detergent-insoluble membrane microdomains. Biochem Biophys Res Commun 232:618-621.

Pfeiffer SE, Warrington AE, Bansal R (1993) The oligodendrocyte and its many cellular processes. Trends Cell Biol 3:191-197.

Puertollano R, Li S, Lisanti MP, Alonso MA (1997) Recombinant expression of the MAL proteolipid, a component of glycolipid-enriched membrane microdomains, induces the formation of vesicular structures in insect cells. J Biol Chem 272:18311-18315.

Rancano C, Rubio T, Correas I, Alonso MA (1994) Genomic structure and subcellular localization of MAL, a human T-cell-specific proteolipid protein. J Biol Chem 269:8159-8164.

Sapirstein VS, Nolan CE, Stern R, Gray-Board G, Beard ME (1992)
Identification of plasmolipin as a major constituent of white matter clathrin-coated vesicles. J Neurochem 58:1372-1378.

Schaeren-Wiemers N, Gerfin-Moser A (1993) A single protocol to detect transcripts of various types and expression levels in neural tissue and cultured cells: in situ hybridization using digoxigenin-labelled cRNA probes. Histochemistry 100:431-440.

Schaeren-Wiemers N, Schaefer C, Valenzuela DM, Yancopoulos GD, Schwab ME (1995a) Identification of new oligodendrocyte- and myelin-specific genes by a differential screening approach. J Neurochem 65:10-22.

Schaeren-Wiemers N, Valenzuela DM, Frank M, Schwab, ME (1995b) Characterization of a rat gene, rMAL, encoding a protein with four hydrophobic domains in central and peripheral myelin. J Neurosci 15:5753-5764.

Schaeren-Wiemers N, van der Bijl P, Schwab ME (1995c) The UDPgalactose:ceramide galactosyltransferase: expression pattern in oligodendrocytes and Schwann cells during myelination and substrate preference for hydroxyceramide. J Neurochem 65:2267-2278.

Scherer SS (1997) Molecular genetics of demyelination: new wrinkles on an old membrane. Neuron 18:13-16.

Scherer SS, Deschenes SM, Xu YT, Grinspan JB, Fischbeck KH, Paul DL (1995) Connexin32 is a myelin-related protein in the PNS and CNS. J Neurosci 15:8281-8294.

Schlesinger MJ (1981) Proteolipids. Annu Rev Biochem 50:193-206.

Shayman JA, Radin NS (1991) Structure and function of renal glycosphingolipids. Am J Physiol 260:F291-302.

Simons K, Ikonen E (1997) Functional rafts in cell membranes. Nature 385:569-572.

Simons K, van Meer G (1988) Lipid sorting in epithelial cells. Biochemistry 27:6197-6202.

Skibbens JE, Roth MG, Matlin KS (1989) Differential extractability of influenza virus hemagglutinin during intracellular transport in polarized epithelial cells and nonpolar fibroblasts. J Cell Biol 108:821-832.

Snipes GJ, Suter U (1995a) Molecular anatomy and genetics of myelin proteins in the peripheral nervous system. J Anat 186:483-494.

Snipes GJ, Suter U (1995b) Molecular basis of common hereditary motor and sensory neuropathies in humans and in mouse models. Brain Pathol 5:233-247.

Snipes GJ, Suter U, Welcher AA, Shooter EM (1992) Characterization of a novel peripheral nervous system myelin protein (PMP-22/SR13). J Cell Biol 117:225-238.

Sommer I, Schachner M (1981) Monoclonal antibodies (O1 to O4) to oligodendrocyte cell surfaces: an immunocytological study in the central nervous system. Dev Biol 83:311-327.

Tole S, Patterson PH (1993) Distribution of CD9 in the developing and mature rat nervous system. Dev Dyn 197:94-106.

van Meer G (1989) Lipid traffic in animal cells. Annu Rev Cell Biol 5:247-275.

Wright MD, Tomlinson MG (1994) The ins and outs of the transmembrane 4 superfamily. Immunol Today 15:588-594.

Zacchetti D, Peranen J, Murata M, Fiedler K, Simons K (1995) VIP17/ MAL, a proteolipid in apical transport vesicles. FEBS Lett 377:465-469. 